\title{
Spin-Crossover Complexes in Direct Contact with Surfaces
}

\author{
Manuel Gruber*(i) and Richard Berndt \\ Institut für Experimentelle und Angewandte Physik, Christian-Albrechts-Universität zu Kiel, \\ Leibnizstr. 19, 24098 Kiel, Germany; berndt@physik.uni-kiel.de \\ * Correspondence: gruber@physik.uni-kiel.de
}

Received: 5 August 2020; Accepted: 24 August 2020 ; Published: 27 August 2020

\begin{abstract}
The transfer of the inherent bistability of spin crossover compounds to surfaces has attracted considerable interest in recent years. The deposition of the complexes on surfaces allows investigating them individually and to further understand the microscopic mechanisms at play. Moreover, it offers the prospect of engineering switchable functional surfaces. We review recent progress in the field with a particular focus on the challenges and limits associated with the dominant experimental techniques used, namely near-edge X-ray absorption fine structure (NEXAFS) spectroscopy and scanning tunneling microscopy (STM). One of the main difficulties in NEXAFS-based experiments is to ascertain that the complexes are in direct contact with the surfaces. We show that molecular coverage determination based on the amplitude of the edge-jump of interest is challenging because the latter quantity depends on the substrate. Furthermore, NEXAFS averages the signals of a large number of molecules, which may be in different states. In particular, we highlight that the signal of fragmented molecules is difficult to distinguish from that of intact and functional ones. In contrast, STM allows investigating individual complexes, but the identification of the spin states is at best done indirectly. As quite some of the limits of the techniques are becoming apparent as the field is gaining maturity, their detailed descriptions will be useful for future investigations and for taking a fresh look at earlier reports.
\end{abstract}

Keywords: spin crossover; single molecule; surfaces; scanning tunneling spectroscopy; near-edge X-ray absorption fine structure

\section{Introduction}

Spin-crossover (SCO) complexes can be switched between two states characterized by different electronic, optical, magnetic and geometric properties [1,2] making these complexes attractive for a wide range of applications [3-6], including smart pigments, actuators [7,8], and data storage [9-14]. In turn, these compounds also hold great promise as sensors [15-20] since the switching may be induced by various parameters such as temperature, light, pressure and current and to a certain extent magnetic field [21].

Considerable effort is presently devoted to preparing SCO complexes on surfaces. The physical and chemical reactivity [22] of such functionalized surfaces may be tuned using various stimuli. Conducting (metal) surfaces are of particular interest as they would allow exploiting the change of (spin-dependent) transport properties of the SCO material. In addition, the control over the SCO complexes could be done electrically, which is certainly advantageous for the down scaling of devices.

SCO compounds in direct contact with surfaces can be investigated in the ultimate limit of single molecules. This may, in principle, reduce the complexity of the system, which is essential for understanding in detail the physical mechanisms at play. Furthermore, the reduction of the dimensionality, the interaction of the complexes with the surface and the possibility to better focus the 
stimulus to the molecules of interest can be of significant advantage and, for instance, turn a compound with poor or no switching properties in the bulk form into a very efficient switch on surfaces [23-25]. However, obtaining intact and functional SCO complexes in direct contact with surfaces turned out to be challenging as briefly exposed below.

To prepare samples with well defined molecule-substrate interfaces deposition in ultra-high vacuum is necessary. Physical vapor deposition, hereafter referred to as sublimation, of the compounds is the most common method because it is available in most surface-science laboratories in contrast to the more complex electrospray ionization deposition [26]. At first glance the sublimation of complexes seems simple. However, these molecules tend to be fragile. Arguably, the first step toward SCO materials on surfaces, was the search for sublimable compounds that remain intact at sublimation temperature. In essence, compounds with rugged coordination bonds between the transition-metal ion and the ligands along with weak intermolecular interactions in the powder form are required. It is, however, difficult to quantitatively measure or predict these quantities, such that the search of sublimable SCO compounds was mostly based on trial and error. To the best of our knowledge, $\mathrm{Fe}(1,10 \text {-phenanthroline })_{2}(\mathrm{NCS})_{2}$ was the first SCO complex to be successfully sublimated [27], followed by nine further compounds (Table 1 and Ref. [28]). The table is expected to grow soon, as several groups are working on newly synthesized SCO compounds. Presently sublimable SCO complexes are based on $\mathrm{Fe}^{2+}$ ions except for the $\mathrm{Fe}^{3+}$ compound 8. Sublimable complexes are not limited to neutral molecules as evidenced by the sublimation of a salt of 8 along with $\mathrm{ClO}_{4}{ }^{-}$counter ions leading to intact 8 on a $\mathrm{Au}(111)$ surface [29].

Table 1. Reported sublimable SCO compounds. For each complex, the year of the first sublimation report is indicated in the column year. Note that several derivatives of these compounds may exist. For instance, at least 8 derivatives of 2 were reported with different substitutions of the phenanthroline ligand. Structural models of the compounds are shown in Figure A1. Abbreviations: phen = 1,10 - phenanthroline, $\mathrm{H}_{2} \mathrm{~B}(\mathrm{pz})_{2}=$ bis(hydrido)bis $\left(1 \mathrm{H}\right.$-pyrazol-1-yl)borate), bipy = 2, $2^{\prime}$-bipyridine, $\mathrm{pz}=$ pyrazolyl, $\mathrm{L}=1-6-[1,1-\mathrm{di}($ pyridin-2-yl)ethyl]-pyridin-2-yl-N, $\mathrm{N}$-dimethylmethanamine, $\mathrm{tz}=$ triazol-1-yl, pap $=\mathrm{N}$-2-pyridylmethylidene-2-hydroxyphenylaminato, pypyr = $2-\left(2^{\prime}-\right.$ pyridyl $)$ pyrrolide and qnal = quinoline - naphthaldehyde.

\begin{tabular}{cccc}
\hline Compound & Formula & Year & Ref(s). \\
\hline 1 & {$\left[\mathrm{Fe}(\mathrm{phen})_{2}(\mathrm{NCS})_{2}\right]$} & 2009 & {$[27,30-35]$} \\
2 & {$\left[\mathrm{Fe}\left(\mathrm{H}_{2} \mathrm{~B}(\mathrm{pz})_{2}\right)_{2}(\mathrm{phen})\right]$} & 2011 & {$[36-46]$} \\
3 & {$\left[\mathrm{Fe}\left(\mathrm{H}_{2} \mathrm{~B}(\mathrm{pz})_{2}\right)_{2}(\mathrm{bipy})\right]$} & 2011 & {$[11,36,37,46-55]$} \\
4 & {$\left[\mathrm{Fe}\left(\mathrm{HB}(\mathrm{pz})_{3}\right)_{2}\right]$} & 2011 & {$[56]$} \\
5 & {$\left[\mathrm{Fe}(\mathrm{NCS})_{2} \mathrm{~L}\right]$} & 2012 & {$[57]$} \\
6 & {$\left[\mathrm{Fe}\left(\left(3,5-\left(\mathrm{CH}_{3}\right)_{2} \mathrm{Pz}\right)_{3} \mathrm{BH}\right)_{2}\right]$} & 2015 & {$[58-63]$} \\
7 & {$\left[\mathrm{Fe}\left(\mathrm{HB}(\mathrm{tz})_{3}\right)_{2}\right]$} & 2017 & {$[10,13,64-66]$} \\
8 & {$\left[\mathrm{Fe}(\mathrm{pap})_{2}\right]^{+}$} & 2017 & {$[29,67]$} \\
9 & {$\left[\mathrm{Fe}\left(\mathrm{pypyr}\left(\mathrm{CF}_{3}\right)_{2}\right)_{2}(\mathrm{phen})\right]$} & 2018 & {$[23,24]$} \\
10 & {$\left[\mathrm{Fe}\left(\mathrm{qnal}_{2}\right)_{2}\right]$} & 2018 & {$[68]$} \\
\hline
\end{tabular}

Most of the compounds listed in Table 1 have been investigated as ultra-thin layers $[24,31,35,37-39,41,42,48,52,57,59,60,62,63,69]$ and single SCO complexes [29,30,32,33,67] on surfaces almost exclusively using (low-temperature) scanning tunneling microscopy (STM) and near-edge X-ray absorption fine structure (NEXAFS) spectroscopy. Besides sublimation, electrospray-ionization deposition has been employed to prepare samples in ultra-high vacuum environments for single-molecule investigations $[25,29,70]$. The main outcomes of these studies are summarized in Refs. [4-6,34,71,72] and in particular Ref. [28] that focuses on sublimable SCO compounds. While reversible switching of individual molecules on surfaces $[25,30,31,38,67]$ as well as nearly full light-induced spin-state conversion of sub-monolayer coverages $[24,41,52,69]$ have been evidenced for a number of systems, the surfaces appears to play a major role for the integrity and functionality of the adsorbed SCO complexes. In short, the strong interaction between the 
molecules and the metal surfaces tends to suppress their spin-state bistability (here we refer to the bistability of a single molecule. In the context of SCO materials, the term bistability is often used to describe the thermal hysteresis of, e.g., the high-spin fraction of a sample) and can even lead to fragmentation [24,39,42,70]. In contrast, sublimable SCO compounds on less metallic substrate, e.g., highly oriented pyrolytic graphite (HOPG), tend to be functional.

Since the prototypical demonstrations of single molecule switching in 2012 [30,38], the field of SCO complexes in direct contact with surfaces has gained a degree of maturity. Detailed investigations of various complexes, in particular on different substrates, along with improved quality of data allowed new discoveries and a better understanding of the mechanisms at play but also challenge the interpretations of some earlier studies. This brief review is intended to highlight the challenges inherent to SCO systems in direct contact with surfaces and the difficulties in interpreting corresponding STM and NEXAFS data.

\section{NEXAFS Methodology for Spin-State Determination and Related Challenges}

The bistability of SCO compounds is associated with two possible electronic configurations of the transition-metal orbitals with $d$ character. In the following, we focus on $\mathrm{Fe}^{2+}$ complexes with octahedral ligand field as it is, by far, the most investigated class of SCO compounds in direct contact with surfaces. The so-called low-spin (LS) state is characterized by a strong ligand field leading to an energy splitting $\Delta_{L S}$ of the $e_{g}$ and $t_{2 g}$ sets of orbitals larger than the electron pairing energy. The six $d$ electrons of the $\mathrm{Fe}^{2+}$ ion fill the $t_{2 g}$ orbitals leading to a total spin $S=0$ (Figure 1a). In contrast, the ligand-field induced energy splitting $\Delta_{H S}$ in the high-spin (HS) state is smaller than the pairing energy, such that the electron filling obeys Hund's rules giving a total spin $S=2$ (Figure 1a).

NEXAFS relies on electronic transitions from a core level (e.g., $p$ orbital) into unoccupied states (e.g., $d$ orbital) induced by the absorption of photons. The technique is element selective since core levels of different elements exhibit characteristic energies. SCO complexes are almost exclusively investigated at the Fe $L_{3}$ and $L_{2}$ edges, respectively corresponding to $2 p^{3 / 2} \rightarrow d$ and $2 p^{1 / 2} \rightarrow d$ transitions, which requires photons with energy ranging from 700 to $730 \mathrm{eV}$. Exemplary XA spectra for a thin film of 9 in the HS (red) and in the LS (blue) states are shown in Figure 1b. Since the occupation of the core level is independent of the spin state, the XA spectra reflect the energy distribution of the unoccupied orbitals, which depends on the spin state (Figure 1a). It should, however, be noted that XA spectra are related to the unoccupied electronic structure but do not show it directly, in particular because the electronic transition leaves a core hole that modifies the electronic states and gives rise to a multiplet structure. The Fe $L_{3}$ edge of the HS state is essentially characterized by a dominant double peak feature (dotted red lines in Figure $1 \mathrm{~b}$ at 706.7 and $707.9 \mathrm{eV}$ ), while that of the LS state is dominated by a single peak at higher photon energy (dotted blue line at $708.0 \mathrm{eV}$ ). It may be worth mentioning that the XA measurements on SCO systems are usually done with particular settings of the beamlines (e.g., defocused beam to avoid beam-induced damages) for which the photon energy is not always well calibrated. This is why small variations of the peak energies can be found in the literature.

The molecules probed by the X-ray beam (typically few millimeters diameter in the defocused mode) are not necessarily in the same spin state. Under the assumption that the complexes are either in the LS or HS state, the resulting XA spectrum $\left(X A S_{\text {mix }}\right)$ is a linear combination of the LS and HS reference spectra $\left(X A S_{\mathrm{LS}}\right.$ and $\left.X A S_{\mathrm{HS}}\right)$ :

$$
X A S_{\text {mix }}=a\left[\gamma_{\mathrm{HS}} X A S_{\mathrm{HS}}+\left(1-\gamma_{\mathrm{HS}}\right) X A S_{\mathrm{LS}}\right]
$$

where $\gamma_{\text {HS }}$ is the fraction of molecules in the HS state and $a$ is a scaling factor that takes into account a potential variation in the quantity of probed molecules. Figure 1c (orange curve) shows such a XA spectrum acquired on a thin film of 9 at $50 \mathrm{~K}$ under illumination with a $532 \mathrm{~nm}$ laser. The fit of the data (dashed black curve in Figure 1c) with Equation (1) using the HS and LS references spectra shown in Figure $1 \mathrm{~b}$ leads to $\gamma_{\mathrm{HS}}=65 \%$. The fit describes the experimental data quite well. This 
procedure is usually repeated for different temperatures with and without illumination, and the corresponding results summarized as shown in Figure 1d. It should be noted that the HS fraction is not necessarily an absolute quantity, but is given relatively to the reference spectra. The black markers describes the evolution of the HS fraction as a function of temperature in the absence of visible-light illumination. From elevated to medium $(\approx 100 \mathrm{~K})$ temperatures, $\gamma_{\mathrm{HS}}$ decreases down to zero as expected for a thermal spin transition.

(a)

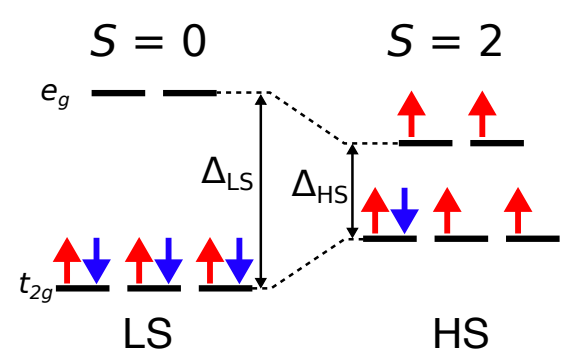

(b)

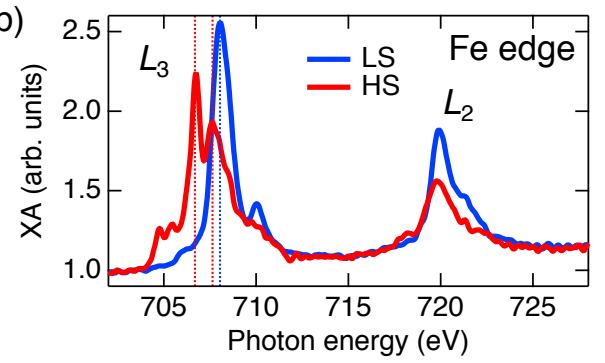

(c)

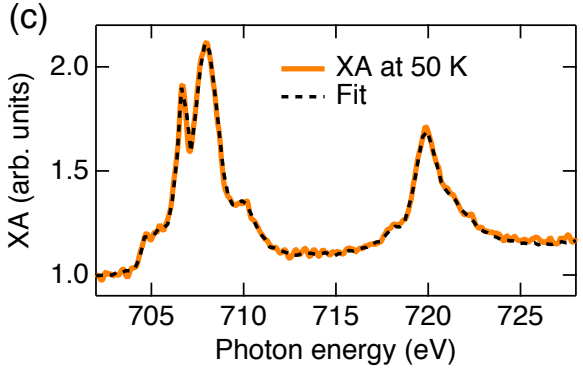

(d)

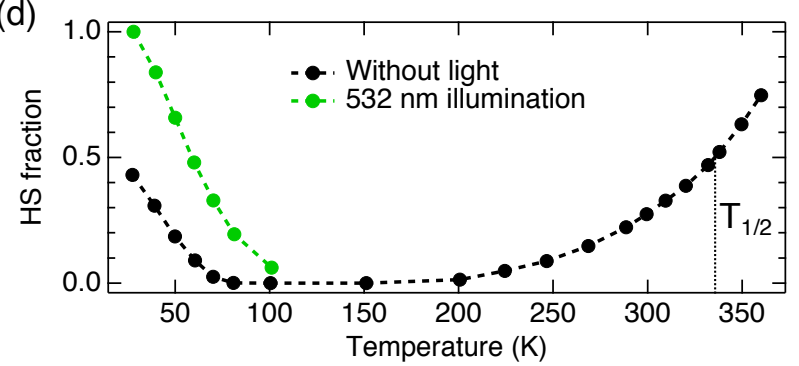

Figure 1. Spin crossover and X-ray absorption spectroscopy methodology. (a) Schematic representation of the electron filling of the $d$ orbitals for a $\mathrm{Fe}^{2+}$ ion in an octahedral ligand field. In the so-called LS state, the energy splitting induced by the ligand field $\left(\Delta_{L S}\right)$ exceeds the electron pairing energy. The electrons occupy the orbitals with $t_{2 g}$ symmetry and the total spin of this configuration is $S=0$ as all the electrons are paired. In the HS state, the energy splitting $\Delta_{H S}$ induced by the ligand field is smaller than the pairing energy. The electron filling obey the Hund's rules, which leads to a total spin $S=2$. (b) XA spectra acquired on $\approx 40$ monolayers (ML) of 9 on $1 T-\mathrm{TiTe}_{2}$ at $28 \mathrm{~K}$ under illumination with a $532 \mathrm{~nm}$ laser (red) and at $120 \mathrm{~K}$ (blue). These spectra are respectively used as a reference for the HS and LS states. The dotted lines are guide to the eye. (c) XA spectrum acquired on the same sample as (b) at $50 \mathrm{~K}$ under illumination (orange). The dashed line is a fit using Equation (1) leading to a HS fraction of $65 \%$. (d) Evolution of the HS fraction as a function of temperature without laser illumination (dark markers) and under illumination with a $512 \mathrm{~nm}$ laser (green markers). The vertical dotted line highlights the transition temperature of the system $T_{1 / 2} \approx 335 \mathrm{~K}$ whereas the dashed lines are guide to the eye. The experimental conditions of $(\mathbf{b}-\mathbf{d})$ are detailed in Ref. [23].

X-ray photons can induce LS to HS switching themselves, a process referred to as soft X-ray induced excited spin-state trapping (SOXIESST) [73]. For temperatures down to $\approx 80 \mathrm{~K}$ the relaxation to the ground state is sufficiently fast, such that the X-ray photons effectively have no effect on $\gamma_{\text {HS }}$. Below $\approx 80 \mathrm{~K}$, this effect is noticeable and a steady-state regime is obtained after some minutes to hours depending on the investigated complex $[52,54,74]$. The black markers in Figure $1 \mathrm{~d}$ correspond to the HS fraction in the steady state, which depends on the X-ray photon flux. It should be noted that HS to LS transitions can be simultaneously driven by the X-ray (reverse SOXIESST [52]). Reverse SOXIESST is generally less efficient and often negligible in comparison to SOXIESST.

A similar and more frequently investigated process referred to as light-induced excited spin-state trapping (LIESST) [75], leads to LS to HS switching at low temperatures upon the absorption of light with suitable wavelength. The green markers in Figure $1 \mathrm{~d}$ represent the steady-state HS fractions for different temperatures as the complexes are illuminated with a $512 \mathrm{~nm}$ laser. Upon illumination with 
adequate wavelength, transitions from the HS to the LS can be induced, and the process referred to as reverse-LIESST [76].

The possibility to directly observe the spin state in NEXAFS experiments is a major advantage for the investigation of SCO systems, in contrast to other methods that rely on indirect observations and methods that may be highly sensitive to impurities in the SCO material or in substrate (e.g., superconducting quantum interference device). In addition, the sensitivity of NEXAFS is sufficiently high to reliably probe fractions of a monolayer of SCO complexes on various (conducting) substrates. NEXAFS is therefore considered as a method of choice to study $\mathrm{SCO}$ compounds in direct contact with substrates and has been extensively used for this purpose $[24,30,31,39,41,42,48,52,57,60,63,69,72]$. However, there are also drawbacks associated with NEXAFS, which are important to keep in mind for a reliable interpretation of the data. In the following, some of the challenges associated with NEXAFS measurements are discussed.

X-rays may not only induce transitions between the spin states but may also damage the SCO complexes. This process is often referred to as soft X-ray induced photochemistry (SOXPC) [52]. As further discussed in Section 6, fragmented molecules may easily be confused with complexes locked in a spin state. Therefore, an evolution of XA spectra is not necessarily related to switching but may reflect an increased number of fragments. SOXPC is relatively common and was observed for all SCO complexes that we investigated. The fragmentation rate not only depends on the photon flux (that we minimized) but also on the compound of interest. We systematically ensured that the fraction of damaged molecules in a measurement remained below a few percents by regularly changing the spot of the sample irradiated by the X-rays (every $20 \mathrm{~min}$ to few hours depending on the investigated compound) and by minimizing the overall exposure of the sample to $\mathrm{X}$-rays.

The element selectivity of NEXAFS allows retrieving a XA solely originating from Fe ions, which is independent, for instance, of the properties of the substrate. This is certainly an advantage but it also makes it difficult to ascertain the purity of SCO materials and the quality (cleanliness) of the surface. In essence, there is no direct way with NEXAFS to ascertain that SCO complexes are in direct contact with the substrates. The complexes may, for instance, be decoupled from the substrate by a thin layer of impurities (see Section 6 for more details). Very low pressures, long degassing of the Knudsen cells and measurements reproduced on several samples may help to diminish this problem.

\section{Thickness Determination in NEXAFS Experiments}

A reliable determination of the molecular-film thickness is one of the largest challenges for SCO systems investigated by NEXAFS. Different methodologies leading to different estimates have been employed. Several reported estimates are therefore necessarily erroneous, and some of the reports of SCO complexes in direct contact with surfaces may actually describe results from multilayer systems. This is why thickness determination is discussed at some length in this section. We first focus on NEXAFS measurements performed in the so-called total electron yield (TEY) mode, for which the absorption signal is given by the current between the sample and ground.

As some NEXAFS end stations are equipped with a STM, it may be possible to calibrate the thickness via STM [24] but the performance of such instruments is usually relatively limited as they are located in noisy environments. Alternatively, samples well characterized with STM may be transported to the synchrotron using a vacuum suitcase [63] provided that the transport process is sufficiently clean. Considering the difficulties associated with STM calibration, it would be challenging to systematically determine the coverage of every sample with STM. In addition, determination of coverages via STM is not always possible, in particular when molecules are diffusing on the surface of interest.

Instead of systematic absolute thickness calibrations, a common approach consists in comparing the $L_{3}$ edge jumps obtained on different samples. However, the comparison is not straightforward and different methodologies were employed, sometimes leading to discrepancies. For XA spectra where the pre-edge is normalized to one, we will show within a rigorous framework that the $L_{3}$ edge jump strongly depends on the substrate. This is verified experimentally, as, for instance, $0.4 \pm 0.2 \mathrm{ML}$ of 9 
leads to an $\mathrm{Fe} L_{3}$ edge jump of $\approx 1 \%$ on $\mathrm{Au}(111)$ (calibrated with STM) and an edge jump of $\approx 3-4 \%$ on HOPG [24]. Assuming a proportional increase of the edge jump with the coverage, $1 \mathrm{ML}$ correspond to edge jumps on the order of $2 \%$ to $3 \%$ and $8 \%$ to $10 \%$ on $\mathrm{Au}(111)$ and HOPG, respectively. For compounds of similar size $\left(\approx 1 \times 1 \times 1 \mathrm{~nm}^{3}\right)$ and with a single $\mathrm{Fe}^{2+}$ ion per molecule, these values may be taken for very rough coverage estimates. It may be worth mentioning that different oxidation or spin states can affect the edge jump.

The substrate dependence of the edge jump can be formally derived. The following part is essentially an extension of the work from Kipgen et al. [69] and consists in deriving the TEY signal of an adsorbate layer atop a substrate. Let us first consider a sample of thickness $t$ with a X-ray absorption coefficient $\mu$. The sample is characterized by an electron escape depth $\lambda$, which corresponds to the average depth from which the electrons reaching the surface of the sample (and likely to contribute to the TEY) originate (in Ref. [77], $\lambda$ is defined as the average depth from which the electrons contributing to the TEY originate. However, the TEY may vary by a sole change of the work function, and in particular without variation of the bulk properties (including $\lambda$ ) of the sample of interest. We adjusted the usual definition of $\lambda$, which is a bulk property of the material, to be independent of the work function) [77]. A monochromatic X-ray beam is directed toward the sample with an angle $\theta$ relative to the surface normal (Figure 2a). The TEY of a slab of the sample of infinitesimal thickness $d z$ at a depth $z$ ( $z=0$ corresponds to the irradiated surface) is given by [77]:

$$
d Y=I_{0} \frac{\mu d z}{\cos \theta} G \exp \left(-\frac{z}{\lambda}\right),
$$

where $d z / \cos \theta$ is the distance traveled by the X-ray beam in the slab, $I_{0}$ the number of incident photons, $I_{0} \mu d z / \cos \theta$ the number of absorption events and $\exp (-z / \lambda)$ describes the probably of an electron at a depth $z$ to reach the surface. $G$ is the product of the electron gain factor, i.e., the average number of electrons generated by a single absorption event, and the (large) fraction of electrons at the surface effectively escaping from the sample (depends on the work function). $G \exp (-z / \lambda)$ therefore describes the number of electrons effectively escaping the sample upon absorption of a single photon at a depth $z$ (Figure 2a). In turn, the TEY of the whole sample reads:

$$
Y=\int_{0}^{t} d Y=I_{0} \frac{\mu}{\cos \theta} G \lambda\left[1-\exp \left(-\frac{t}{\lambda}\right)\right] .
$$

The TEY of a semi infinite sample is obtained by taking the limit $t \rightarrow \infty$ :

$$
Y=I_{0} \frac{\mu}{\cos \theta} G \lambda
$$

Equations (2)-(4) assume that the number of X-ray photons is the same in every slab. This hypothesis is valid for $\lambda \ll \cos \theta / \mu$ but also for very thin films $t \ll \cos \theta / \mu(1 / \mu \approx 20 \mathrm{~nm}$ for bulk Fe at the $L_{3}$ edge [77]).

For a sample composed of a layer of thickness $t_{A}$ with properties $\mu_{A}, \lambda_{A}, G_{A}$ adsorbed on a semi-infinite substrate $\left(\mu_{S}, \lambda_{S}, G_{S}\right)$, the TEY reads:

$$
Y_{\text {sample }}=I_{0} \frac{\mu_{A}}{\cos \theta} G_{A} \lambda_{A}\left[1-\exp \left(-\frac{t_{A}}{\lambda_{A}}\right)\right]+I_{0} \frac{\mu_{S}}{\cos \theta} G_{S} \lambda_{S} \exp \left(-\frac{t_{A}}{\lambda_{A}}\right) .
$$

To keep the notations simple, we use $G_{S}$ in the second term of Equation (5). However, the presence of the adsorbate layer can change the work function of the substrate and hence $G_{S}$. In addition, it is important to remember that the work function change and therefore $G_{S}$ depends on $t_{A}$ for sub-ML coverage. To track the change of the X-ray intensity during measurements, the TEY of a grid (with properties $\mu_{G}, \lambda_{G}$ and $G_{G}$ ) is simultaneously recorded and has the following expression:

$$
Y_{\text {grid }}=I_{0}^{\prime} \mu_{G} G_{G} \lambda_{G}
$$


where $I_{0}^{\prime}$ effectively describes the number of photons incident to the grid (and not those passing through the holes of the grid). Introducing $\bar{\mu}_{A}=\mu_{A} G_{A}, \bar{\mu}_{S}=\mu_{S} G_{S} \lambda_{S} / \lambda_{A}$ and $\bar{\mu}_{G}=\mu_{G} G_{G} \lambda_{G} / \lambda_{A}$, the TEY of the sample normalized to that of the grid, the quantity generally measured in NEXAFS, reads:

$$
Y_{\text {sample }} / Y_{\text {grid }}=\frac{\bar{\mu}_{A}\left[1-\exp \left(-\frac{t_{A}}{\lambda_{A}}\right)\right]+\bar{\mu}_{S} \exp \left(-\frac{t_{A}}{\lambda_{A}}\right)}{\bar{\mu}_{G} \cos \theta} \frac{I_{0}}{I_{0}^{\prime}} .
$$

Figure $2 \mathrm{~b}$ shows an exemplary measurement of $Y_{\text {sample }} / Y_{\text {grid }}$ as a function of the photon energy for 0.4 ML 9 on $\mathrm{Au}(111)$.

The edge jumps are usually given from XA spectra normalized to the pre-edge signal $\left(Y_{\text {sample }}^{\text {pre }} / Y_{\text {grid }}\right)$, and we have:

$$
\frac{Y_{\text {sample }} / Y_{\text {grid }}}{Y_{\text {sample }}^{\text {pre }} / Y_{\text {grid }}}=\frac{1+\left[\exp \left(\frac{t_{A}}{\lambda_{A}}\right)-1\right] \frac{\bar{\mu}_{A}}{\bar{\mu}_{S}}}{1+\left[\exp \left(\frac{t_{A}}{\lambda_{A}}\right)-1\right] \frac{\bar{\mu}_{A}}{\bar{\mu}_{S}}} \stackrel{\frac{t_{A}}{\lambda_{A}}}{\approx} \ll \frac{1+\frac{t_{A}}{\lambda_{A}} \frac{\bar{\mu}_{A}}{\bar{\mu}_{S}}}{1+\frac{t_{A}}{\lambda_{A}} \frac{\bar{\mu}_{A}^{\text {pre }}}{\bar{\mu}_{S}}},
$$

where $\bar{\mu}_{S}, \lambda_{S}, \bar{\mu}_{G}, \lambda_{G}$ and $\lambda_{A}$ are assumed to be constant in the energy range of interest (for low coverages, the approximation of constant $\bar{\mu}_{S}$ is not always fulfilled. This is, for instance, visible in Figure $2 \mathrm{~b}$ where the slope is essentially due to the variation $\bar{\mu}_{S}$ with energy. For simple evolutions of $\bar{\mu}_{S}$ (e.g., linear), the background of the XA spectra can be corrected, and the discussion on the edge jump remains valid). In the low coverage regime $\left(t_{A} / \lambda_{A} \ll 1\right)$ and assuming that $\bar{\mu}_{A}^{\mathrm{pre}} / \bar{\mu}_{S}$ is not excessively large. This assumption appears reasonable for a molecular layer atop a noble metal or HOPG and photon energy $\approx 700 \mathrm{eV}$. We have $\mu_{A, S}=\sigma_{A, S} n_{A, S}$ where $\sigma_{A, S}$ and $n_{A, S}$ are respectively the absorption cross sections and densities of the adsorbate layer $A$ and substrate $S$ [78], and therefore $\bar{\mu}_{A} / \bar{\mu}_{S}=\left(\sigma_{A} n_{A} G_{A} \lambda_{A}\right) /\left(\sigma_{S} n_{S} G_{S}^{\prime} \lambda_{S}\right)$. Assuming that the adsorbate layer is mostly composed of carbon atoms, we can consider $\sigma_{A} / \sigma_{S} \lesssim 1$ as the cross section of carbon is typically lower than that of metal at photon energy $700 \mathrm{eV}$. The adsorbate layer has typically a lower density than that of bulk substrates, such that $n_{A} / n_{S} \lesssim 1$. The electron escape depth of bulk metals is on the order of $\lambda_{S} \approx 2 \mathrm{~nm}$ [79], while that of a molecular layer is on the order of 9 ML [69] (determined for 3, which corresponds to $\lambda_{A} \geq 10 \mathrm{~nm}$ ), such that $\lambda_{A} / \lambda_{S} \lesssim 1$. The factor $G_{A} / G_{S}$ is challenging to accurately determine but may be roughly estimated from secondary electron yields ( $\approx 1$ for HOPG [80] and $\approx 1.6$ for Au [81]), which suggest $G_{A} / G_{S} \lesssim 1$. In conclusion, for a molecular layer atop a metal substrate or atop HOPG $\bar{\mu}_{A} / \bar{\mu}_{S} \lesssim 1$ is likely so that $t_{A} \bar{\mu}_{A}^{\mathrm{pre}} /\left(\lambda_{A} \bar{\mu}_{S}\right) \ll 1$, Equation (8) can be further simplified such that the edge jump reads:

$$
\frac{Y_{\text {sample }} / Y_{\text {grid }}}{Y_{\text {sample }}^{\text {pre }} / Y_{\text {grid }}}-1 \approx \frac{\bar{\mu}_{A}-\bar{\mu}_{A}^{\text {pre }}}{\bar{\mu}_{S}} \frac{t_{A}}{\lambda_{A}}=\frac{\left(\mu_{A}-\mu_{A}^{\text {pre }}\right)}{\mu_{S}} \frac{G_{A}}{G_{S}} \frac{t_{A}}{\lambda_{S}} .
$$

As may be expected, the edge jump (of an adsorbate element) is found to depend on the adsorbate coverage $t_{A}$. However, the denominator of the edge jump is directly related to the substrate X-ray absorption coefficient $\mu_{S}$ and electron escape depth $\lambda_{S}$. Furthermore, $G_{S}$, which depends on the work function of the substrate, is a function of $t_{A}$. It turns out that reliable thickness estimates based on the edge jump of XA spectra normalized to the pre-edge are challenging and in particular $\mu_{S}$ and $G_{S}$ have to be taken into account. XA spectra normalized to the pre-edge (signal at $700 \mathrm{eV}$ ) of 9 in the LS (blue) and in the HS (red) states are shown in Figure 2c. While the measurements were done on the very same sample, the $L_{3}$ edge jump evolves from $\approx 4 \%$ in the LS state to $\approx 3 \%$ in the HS state. We cannot exclude that different areas of the sample with different local coverages were probed. Nevertheless, the data in Figure $2 \mathrm{c}$ indicate that the edge jump depends on the spin state. In such cases, the integral of the edge rather than the jump should be considered. 

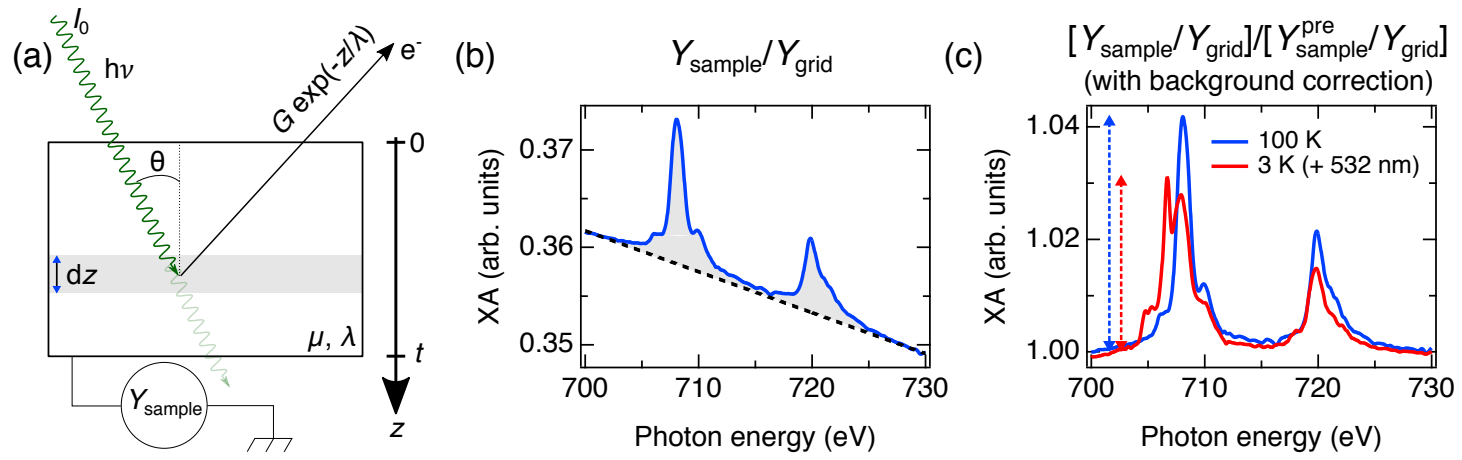

Figure 2. Schematic of a X-ray absorption event and typical XA spectra. (a) A sample of thickness $t$ is irradiated with a number $I_{0}$ of X-ray photons of energy $h v$ incoming at an angle $\theta$ relative to the surface normal. The sample is characterized by an absorption coefficient $\mu$ and an electron escape depth $\lambda$. The schematic depicts the absorption of a single photon in a slab (gray area) of thickness $d z$, which leads to $G \exp (-z / \lambda)$ electrons exciting the sample as represented by an arrow. A number $Y_{\text {sample }}$ of electrons flowing from ground compensates the electron emission into vacuum and serves to measure the absorption. $G$ is the product of the electron gain factor with the fraction of electrons at the surface effectively escaping from the sample (see text). Note that photoelectrons in principle are emitted in all directions. (b) $Y_{\text {sample }} / Y_{\text {grid }}$ versus photon energy acquired on $0.4 \mathrm{ML}$ of 9 on HOPG at $100 \mathrm{~K}$ (solid curve) [24]. The background originating from the HOPG is modeled by a slope in the energy range of interest (dashed curve). (c) Normalized XA spectrum $\left[Y_{\text {sample }} / Y_{\text {grid }}\right] /\left[Y_{\text {sample }}^{\text {pre }} / Y_{\text {grid }}\right]$ obtained from the data shown in (b) after correction of the background (blue curve). Another normalized XA spectrum (complexes in the HS state), obtained from similar measurements as in (b) but at $3 \mathrm{~K}$ under illumination with a $532 \mathrm{~nm}$ laser on the very same sample, is shown in red. The colored double arrows depict the respective $L_{3}$ edge jumps.

An alternative approach to estimate the thickness is to consider the edge jumps of spectra solely normalized to the TEY of the grid and in particular not normalized to the pre-edge. The edge jump then reads:

$$
\begin{aligned}
Y_{\text {sample }} / Y_{\text {grid }}-Y_{\text {sample }}^{\text {pre }} / Y_{\text {grid }} & =\frac{\bar{\mu}_{A}-\bar{\mu}_{A}^{\text {pre }}}{\bar{\mu}_{G} \cos \theta}\left[1-\exp \left(-\frac{t_{A}}{\lambda_{A}}\right)\right] \frac{I_{0}}{I_{0}^{\prime}} \\
& =\frac{\mu_{A}-\mu_{A}^{\text {pre }}}{\mu_{G} \cos \theta} \frac{G_{A}}{G_{G}} \frac{\lambda_{A}}{\lambda_{G}}\left[1-\exp \left(-\frac{t_{A}}{\lambda_{A}}\right)\right] \frac{I_{0}}{I_{0}^{\prime}} .
\end{aligned}
$$

It is here important to note that measurements performed at different beamlines (even with the same type of grid) or a change of settings of a given beamline can lead to different ratios $I_{0} / I_{0}^{\prime}$. However, for unchanged beamline conditions, Equation (11) may be simplified to:

$$
Y_{\text {sample }} / Y_{\text {grid }}-Y_{\text {sample }}^{\text {pre }} / Y_{\text {grid }}=\frac{C}{\cos \theta}\left[1-\exp \left(-\frac{t_{A}}{\lambda_{A}}\right)\right],
$$

where $C=\left[\left(\mu_{A}-\mu_{A}^{\mathrm{pre}}\right) G_{A} \lambda_{A} I_{0}\right] /\left[\mu_{G} G_{G} \lambda_{G} I_{0}^{\prime}\right]$. Equation (12) can be employed to tentatively compare thicknesses for measurements performed at the same beamline, and ideally during the same beamtime, provided that $\lambda_{A}$ and $\mu_{A}$ remain constant on the different substrates. Different growth modes of the molecules or different magnetic fields on the sample may effectively lead to a change in $\lambda_{A}$. In addition, the condition on $\mu_{A}$ implies that the number of $d$ holes of the investigated adsorbate element (e.g., $\mathrm{Fe}$ ) stays constant, i.e., the investigated metal element should have the same oxidation state on the different substrates. Equation (12) may actually be integrated over the entire edge to minimize the influence of multiplet features. An example with varying background is shown in Figure $2 b$. The useful signal for coverage determination is colored in gray, which can be, for instance, integrated over the $L_{3}$ edge. 
Kipgen et al. have experimentally shown the thickness dependence of Equation (12) for various amount of 3 on HOPG. In Ref. [24] , we have compared 0.4 ML of 9 on $\mathrm{Au}(111)$, graphene/Ni(111), $\mathrm{HOPG}$ and $\mathrm{WSe}_{2}$. The thickness was calibrated via STM for the molecules on $\mathrm{Au}(111)(0.4 \pm 0.2 \mathrm{ML})$, while the other samples were prepared in similar conditions where the deposition rate was verified before and after deposition using a quartz microbalance. As expected from Equation (12), we found that the integrated $\mathrm{Fe} L_{3}$ edge is approximately equal (less than $35 \%$ variation) on different samples. The observed deviations may be due to differences in the HS fraction, to small variations of the coverage of the different samples, and to undesired (small) changes of the beamline conditions.

The substrate independence as well as the exponential dependence of the edge jump on the adsorbate thickness have essentially been experimentally verified, such that Equation (12) appears to be applicable for thickness estimations. It is, however, based on a relative comparison to a calibrated sample, which needs to be measured under the same conditions. Furthermore, given the uncertainty associated with the calibration of the reference sample that may be significant even with STM, and the possible deviation from a layer-by-layer growth mode, we believe coverages of $0.5 \mathrm{ML}$ and ideally even lower coverages would be required to ensure that the investigated molecules are in direct contact with the substrate.

\section{Fragmentation of SCO Complexes on Metal Substrates}

To prepare functional SCO complexes on surfaces it is not a sufficient to synthesize compounds that withstand sublimation. Electronic decoupling between the molecules and metal substrates was shown to be important for their functionality [29-31,38]. It turned out from detailed investigations discussed below that the molecule-substrate interaction can be significant and lead to the fragmentation of the complex. As a result, the preparation of intact and functional SCO compounds on metal surfaces appears to be a challenge. So far only three STM-based studies demonstrated the switching of SCO complexes in direct contact with a metal surface $[25,29,60]$, while other reports were based on NEXAFS experiments with the related question on the investigated coverage (see Section 3). It may be worth mentioning that the nature of the switching was not unambiguously determined in Refs. [25,29], potentially further reducing the number of SCO systems on metals.

We performed experiments on a Fe(terpyridine) ${ }_{2}$ derivative 11 (Figure 3a), which has shown indications of switching in a mechanically controlled break-junction [82,83], to probe the role of the substrate in the fragmentation process. Using a home-built electrospray ionization setup [26], 11 was brought in the gas phase from solution and its integrity verified with an in line mass spectrometer. A typical mass spectrum in the configuration to maximize transmission (at the cost of energy resolution) is shown in Figure $3 \mathbf{b}$ and exhibits two main peaks. The first peak, with the largest amplitude, corresponds to doubly charged, intact 11 (calculated $m / z$ of $524 \mathrm{u} / \mathrm{e}$ ) while the second peak is compatible with a singly charged single terpyridine ligand attached to Fe (calculated $m / z$ of $552 \mathrm{u} / \mathrm{e}$ ). Therefore, while a small fraction $(<10 \%)$ of the molecules dissociate during the spraying, most of them are intact. The mass spectrometer was then configured so as to only transmit intact complexes toward a $\mathrm{Au}(111)$ sample. We nevertheless exclusively observed fragments on $\mathrm{Au}(111)$ with low-temperature STM [70]. Approximately half of the adsorbates were identified as Fe attached to a single terpyridine ligand. The remaining adsorbates are compatible with isolated terpyridine ligands, which we found in three different conformations (Figure $3 \mathrm{c}-\mathrm{h}$ ). 
(a)

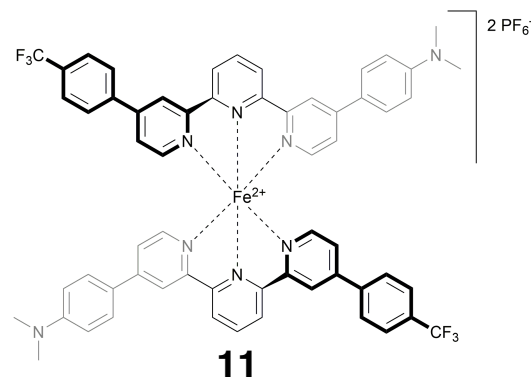

(b)

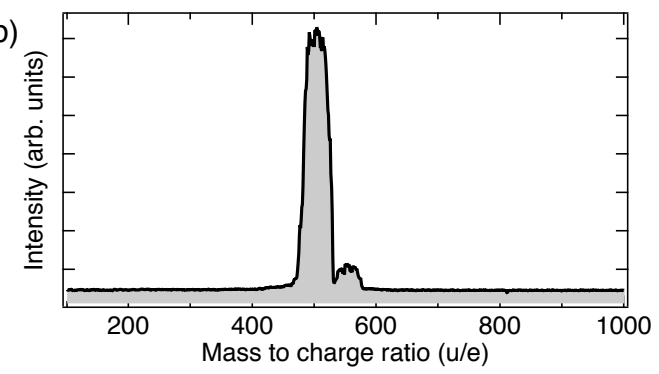

$20 \mathrm{pm}$

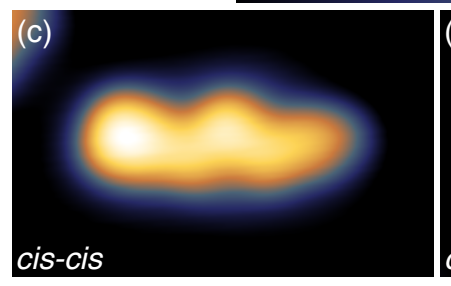

$\mathrm{Me}_{2} \mathrm{~N}$

(f)

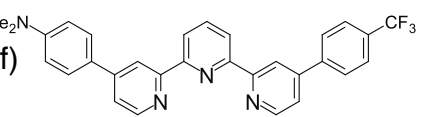

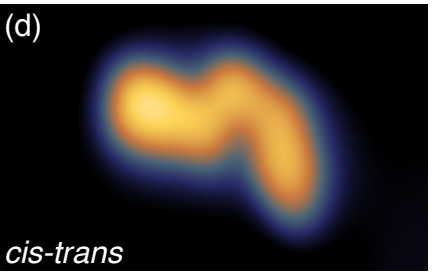

(g)

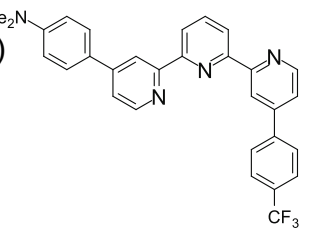

$170 \mathrm{pm}$

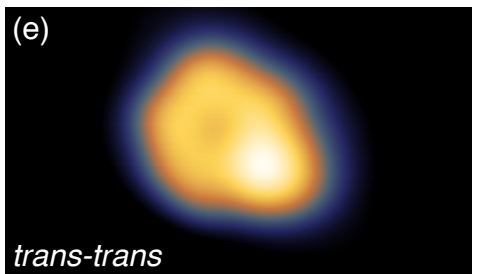

(h)

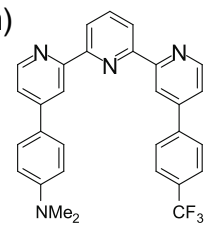

Figure 3. Fragmentation of 11 on $\mathrm{Au}(111)$. (a) Molecular structure of 11 composed of two $2,2^{\prime}: 6^{\prime}, 2^{\prime \prime}$-terpyridine ligands with 4-(trifluoromethyl)phenyl and 4- $N, N$-dimethylaniline substituents. The complex has a charge +2 , which is compensated by hexafluorophosphate $\left(\mathrm{PF}_{6}^{-}\right)$counter ions in the powder form. (b) Typical mass spectrum of 11 obtained upon electrospray ionization exhibiting peaks centered at $m / z=505$ and $555 \mathrm{u} / \mathrm{e}$. The spectrometer was operated in a low resolution mode to maximize the transmission of the ions to the $\mathrm{Au}(111)$ surface. Low-resolution measurements lead to peaks with significant width $(\approx 40 \mathrm{u} / \mathrm{e})$ and a deviation of the measured and calculated mass-to-charge ratios. The first peak is attributed to intact, doubly charged complexes 11 (calculated charge-to-mass ratio of $524 \mathrm{u} / \mathrm{e}$ ). (c-e) STM topographs ( $4.5 \mathrm{~nm}$ wide) of terpyridine ligands in different conformations observed upon deposition of 11 on $\mathrm{Au}(111)$. A common color scale is shown above the topographs. $(\mathbf{f}-\mathbf{h})$ Structural models of the terpyridine conformers observed in the STM topographs (c-e). Further experimental details can be found in Ref. [70].

To prevent fragmentation, a reinforced compound, in which the two terpyridine ligands are covalently connected with two linkers, was synthesized and deposited on $\mathrm{Au}(111)$ [70]. While the ligands remained together, we observed a significant flattening of the molecule, which breaks the coordination sphere of the Fe and hence the functionality of the complex. The fragmentation and flattening of the respective complexes on $\mathrm{Au}(111)$ are most likely due to molecule-substrate van der Waals interactions. It should be noted that physisorption (induced by van der Waals interactions) is sometimes incorrectly assumed to be weak. The adsorption energy of physisorbed relatively small molecules can be on the order of a few electronvolts [84,85].

Further reinforcement of the compound, with four linkers in total, is required to leave the complexes intact in a $\mathrm{Au}(111)$ surface [25]. While the compound is then relatively rigid and do no more exhibit SCO in the bulk, individual complexes are reversibly switched by injection of electrons at elevated sample voltages $(V \gtrsim 0.9 \mathrm{~V})$.

Substrate-induced fragmentation of SCO complexes has alternatively been inferred from investigations on various substrates. The first evidence dates from 2012 as Gopakumar et al. have shown, in a combined study with STM and NEXAFS, that 2 on $\mathrm{Au}(111)$ is fragmented [39] while complexes in the second layer exhibit reversible electron-induced switching [38]. The molecules withstand sublimation as they are intact in the second layer and in thicker films $[36,86]$. 
However, their interactions with $\mathrm{Au}(111)$, considered as a chemically inert surface, lead to fragmentation. This trend was confirmed with 2 and a derivative of 2 deposited on $\mathrm{Au}(111)$ and $\mathrm{Bi}(111)$ [42]. While only fragments are found on $\mathrm{Au}(111)$, switching of a fraction of the molecules is observed on $\mathrm{Bi}(111)$. These different behaviors on the two surfaces are most likely related to differences in the strength of the van der Waals forces between the molecules and the substrate. Compared to $\mathrm{Au}(111), \mathrm{Bi}(111)$ has a lower density of states at the Fermi level, which presumably reduces the van der Waals interaction [42].

A similar observation was made with compound 9 (Figure 4a) [24]. The XA spectrum 0.4 ML of 9 on $\mathrm{Au}(111)$ (Figure $4 \mathrm{~b}$ ) exhibits no characteristic feature that are expected for SCO complexes (see Figure 1b). The spectrum rather is indicative of fragmented complexes in agreement with STM data [24]. Accordingly, no evolution of the spectrum is observed upon variation of the temperature. In contrast, the deposition of the same quantity of 9 under the same conditions on HOPG leads to intact and functional SCO compounds (Figure 4c). The XA spectrum acquired at $100 \mathrm{~K}$ (blue) is characteristic to that of the complexes in the LS state, while the spectrum obtained at $3 \mathrm{~K}$ under laser illumination (red) has the expected features of the HS state (fraction of HS molecules of 95\%). The substrate can apparently have a drastic influence on the integrity and functionality of SCO complexes. It should be noted that the XA spectrum of the fragmented molecules (Figure $4 \mathrm{~b}$ ) peaks at $706.6 \mathrm{eV}$, while that of HS complexes is maximal at $706.7 \mathrm{eV}$. Fragmented molecules may therefore easily be confused with HS complexes in noisy spectra, especially when intact complexes are measured along with fragmented ones. It should also be mentioned that XA spectra on other fragmented molecules may be different from that shown in Figure 4b, as the XA spectrum depends on the environment and oxidation state of the Fe ion.

(a) $\mathrm{F}$

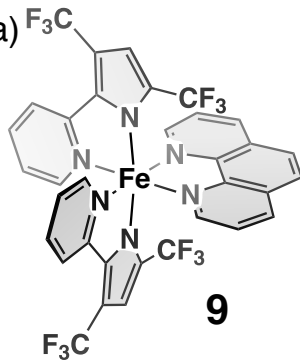

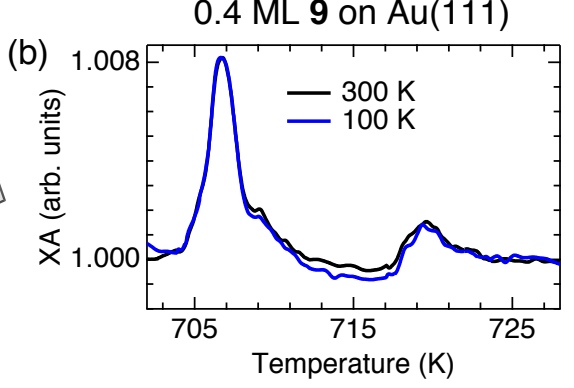

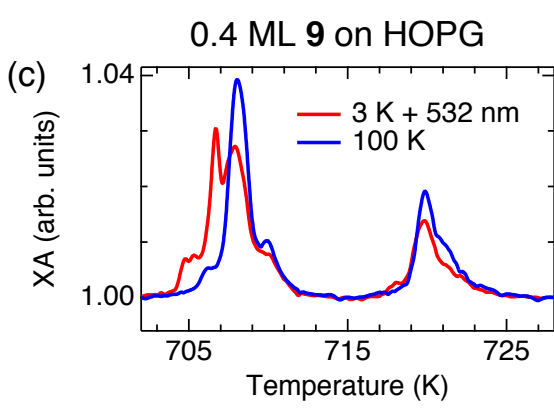

Figure 4. (a) Structural model of 9. XA spectra on (b) Au(111) and (c) HOPG upon deposition of $0.4 \mathrm{ML}$ of compound 9. The spectra acquired on $\mathrm{Au}(111)$ are indicative of fragmented molecules (see Ref. [24]) and accordingly show no evolution with temperature (compare blue and black spectra in (b) respectively acquired at 100 and $300 \mathrm{~K}$ ). In contrast, the spectra acquired on HOPG exhibit the expected features of $\mathrm{Fe}^{2+}$ in an octahedral ligand field. The $\mathrm{HS}$ fraction evolves from $\approx 0 \%$ at $100 \mathrm{~K}$ to $\approx 95 \%$ at $3 \mathrm{~K}$ (under illumination with a $532 \mathrm{~nm}$ laser), as expected for intact complexes 9 . Further experimental details can be found in Ref. [24].

Deposition of complexes on more reactive surfaces, such as $\mathrm{Co} / \mathrm{Cu}(100)$, has so far systematically led to the (partial) fragmentation of the complexes. This was shown for 1, intact on $\mathrm{Au}(111), \mathrm{Cu}(111)$, $\mathrm{Cu}(100)$ and $\mathrm{Cu}_{2} \mathrm{~N} / \mathrm{Cu}(100[30,34,35]$ and for 9 intact on HOPG and WSe 2 [24].

STM investigations on fragmented SCO complexes $[24,33,39,42,70]$ identified isolated ligands on the surfaces, indicating that the dissociation occurs at the (weak) coordination bonds. The Fe ion may remain attached to other ligands or split off as a single atom, and, e.g., move to a step of the substrate [70]. For more robust SCO compounds, much stronger coordination bonds are not desirable as they most probably will disturb the critical energy balance between the HS and LS states. An alternative approach is to employ ligands with more coordination bonds to the metal ion, e.g., tridentate ligands. Furthermore, as van der Waals forces are believed to cause the fragmentation, small three-dimensional compounds may be more suitable than complexes with extended planar 
ligands. Alternatively, substrates with lower density of states at the Fermi level, such as $\mathrm{WSe}_{2}$ and $\mathrm{HfS}_{2}$ layered materials, may be used [24].

\section{Spin-State Coexistence}

In some SCO materials, some molecules are locked in a given state, and the corresponding (thermal) spin transition is not complete. For instance, SCO nanoparticles may exhibit a residual fraction of HS complexes at low temperatures, where the residual fraction is found to depend on the nanoparticle size [87-89]. Félix et al. rationalized these results on nanoparticles with a thermodynamic model of a core-shell nanoparticle, where the core and shell are described with different surface energies [90]. At the microscopic level, a difference in the surface energies is the result of different environments of the SCO complex, e.g., varying number of nearest-neighbors and stress induced by neighbors. SCO complexes in direct contact with surfaces are in a environment completely different to that from the bulk form, such that different ground state or a coexistence of HS and LS species may be observed.

Miyamachi et al. observed a coexistence of HS and LS species of 1 on $\mathrm{Cu}(100)$ [30]. The spin state of the complexes is likely to be determined by the adsorption site of the molecule on the surface as the HS and LS states are characterized by different adsorption sites [31,32,34,91]. A modification of the adsorption site is believed to be associated with an excessive energy cost, which suggests that the spin state of the complex is determined during adsorption and essentially immutable (switching attempts were unsuccessful). Coexistence of HS and LS states of 1 has also been observed on $\mathrm{Cu}(111)$ and $\mathrm{Au}(111)[32,34]$. The coexistence is, however, limited to the first ML while second-ML molecules are in the HS state $[31,32,34]$.

Pronschinske et al. reported on the spatial modulation of the electronic properties of a bilayer film of 3 on $\mathrm{Au}(111)$, which is interpreted as a coexistence of HS and LS compounds within the film [49]. As HS and LS complexes have different geometries, the authors suggested that the spin state of the second-ML molecules is adjusted to maximize the preferred $\pi$-stacking with first-ML molecules. The spin-state coexistence would hence result from a minimization of the adsorption energy.

Using NEXAFS spectroscopy, Warner et al. reported on the spin-state coexistence of 3 adsorbed on $\mathrm{Au}(111)$ with a residual $\mathrm{HS}$ fraction of $\approx 50 \%$ at low temperatures [48]. In contrast, compound 2 and a derivative of 2 fragment on $\mathrm{Au}(111)$. However, a spin-state coexistence is observed for a sub-monolayer coverage of 2 on $\mathrm{Bi}(111)$ with a residual HS fraction of $\approx 50 \%$ at low temperatures [42].

The most complete investigation of spin-state coexistence so far was carried out on sub-ML coverage of 6 (Figure 5a) on $\mathrm{Au}(111)$ using STM, NEXAFS and grazing incidence X-ray diffraction along with density functional theory calculations $[59,62,63]$. The molecules assemble into large single-layer islands and are imaged as protrusions (reddish areas in the inset to Figure $5 b$ ) at negative sample voltage. However, only one every three molecules is observed as a protrusion at positive sample voltage $(+0.3 \mathrm{~V})$ (Figure $5 \mathrm{~b})$. There are two types of molecules (visible/invisible at $+0.3 \mathrm{~V})$, which are associated to molecules in different spin states. In line with this association, illumination of the sample with a $405 \mathrm{~nm}$ laser diode leads to a complex spin-switching dynamics where further molecules become visible at positive sample voltage [59]. Sub-ML coverage of 6 therefore exhibits a spin-state coexistence, which is also observed in NEXAFS measurements. Figure 5c shows a XA spectrum of 6 on Au(111) at $4 \mathrm{~K}$. Fit of the spectrum with HS and LS reference spectra leads to a HS fraction of $66 \%$, which is consistent with $1 / 3$ of the molecules appearing differently to the remaining $2 / 3$.

Grazing incidence X-ray diffraction measurements on the same sample revealed an epitaxial relation between the molecular layer and the substrate, indicating that certain adsorption sites are favorable to the molecules [62]. Therefore, the spin switching of molecules within the layer would not only induce a stress on neighboring molecules due to the volume change of the molecule associated with the switching, but would also perturb the epitaxial relationship with the substrate. Fourmental et al. [62] have developed a mechanoelastic model where the intermolecular and molecule-substrate interactions are described by springs of spring constants $k_{\mathrm{mol}}$ and $k_{\mathrm{sub}}$, respectively. 
The HS fraction, estimated from Monte-Carlo calculations, evolves from 0 to 0.8 with increasing values of the ratio $k_{\mathrm{sub}} / k_{\mathrm{mol}}$. Within this simplified model, the ratio $k_{\mathrm{sub}} / k_{\mathrm{mol}}$ is controlling the spinstate coexistence.

(a)

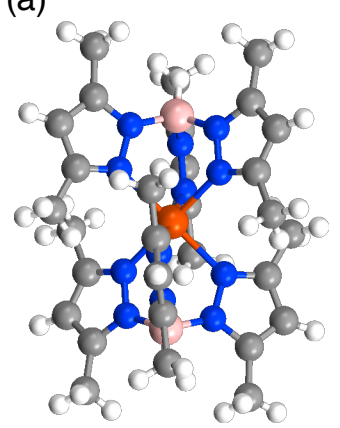

6
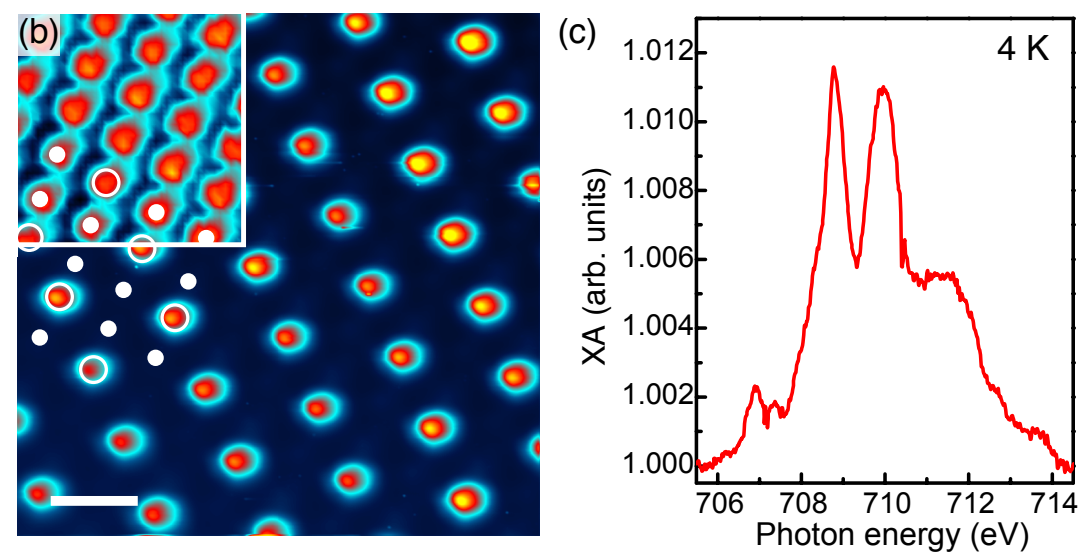

Figure 5. Coexistence of HS and LS complexes in sub-monolayer coverages of 6 on $\mathrm{Au}(111)$ at $4 \mathrm{~K}$. (a) Schematic of compound 6 where orange, blue, gray, pink and white spheres represent Fe, N, C, $\mathrm{B}$ and $\mathrm{H}$ atoms, respectively. (b) Constant-height STM topograph $(0.3 \mathrm{~V}, 12 \mathrm{~nm}$ wide) of a single layer of 6 on $\mathrm{Au}(111)$. The inset shows a STM topograph acquired at a sample voltage of $-1.5 \mathrm{~V}$ where each protrusion corresponds to a single complex 6 . At a positive sample voltage of $0.3 \mathrm{~V}$, however, only one out of three molecule is observed as a protrusion. The presence or absence of protrusion at $0.3 \mathrm{~V}$ is related to the spin state of the imaged complexes. (c) XA spectra of $\approx 0.5 \mathrm{ML}$ on $\mathrm{Au}(111)$ taken at $4 \mathrm{~K}$. The HS fractions, inferred from a fit, is $\approx 66 \%$. $(\mathbf{a}, \mathbf{b})$ are adapted from Ref. [59] (under CC BY) with permission from the authors. (c) is adapted from Ref. [63] with permission. Copyright 2020, John Wiley and Sons.

From the investigations described above, the molecule-substrate interaction appears to be crucial for the spin-state coexistence. For 1, the spin state of a single molecule is suggested to be determined from the adsorption sites of the thiocyanate groups on $\mathrm{Cu}(100), \mathrm{Cu}(111)$ and $\mathrm{Au}(111)[31,34]$. The large adsorption energy and the probably high energy cost associated with a change of adsorption site are most likely the reasons for the stability of the spin states and their insensitivity to the various applied stimuli $[30,31,34]$. For 6 , the molecule-substrate interaction seems to be moderate as the complexes form islands and may be switched [59]. The phase of coexisting HS and LS complexes (Figure 5b) is the one that minimizes the spin-state energy, the intermolecular and the molecule-substrate interaction energies.

\section{Distinction between Fragmentation and Spin-State Coexistence}

While spin-state coexistence in sub-ML coverages of SCO compounds on surfaces has been clearly evidenced, we will show that this effect may easily be confused in NEXAFS experiments with the presence fragmented molecules.

Figure 6a shows XA spectra acquired on $0.4 \mathrm{ML}$ of 9 on a graphene/Ni(111) surface for different temperatures under illumination with a $532 \mathrm{~nm}$ laser [24]. The HS fraction, inferred from fits to Equation (1) (red curves in Figure $6 \mathrm{~b}$ ), is $\approx 0.5$ from 80 to $250 \mathrm{~K}$ and gradually increases to 1 as the temperature is reduced below $80 \mathrm{~K}$ (red markers in Figure 6c). Since 9 is nominally a LS compound with a transition temperature well above room temperature, the thermal evolution of the HS fraction is as expected if one considers approximately half of the molecules locked in the HS state. However, a closer inspection of the fitted curves reveals small deviations from the experimental data (see arrows in Figure 6b). It should be noted that in several comparable experiments (similar investigated coverage), the noise level of the data is comparable to or larger than the observed deviations, such that the fit with Equation (1) would be considered as acceptable. 

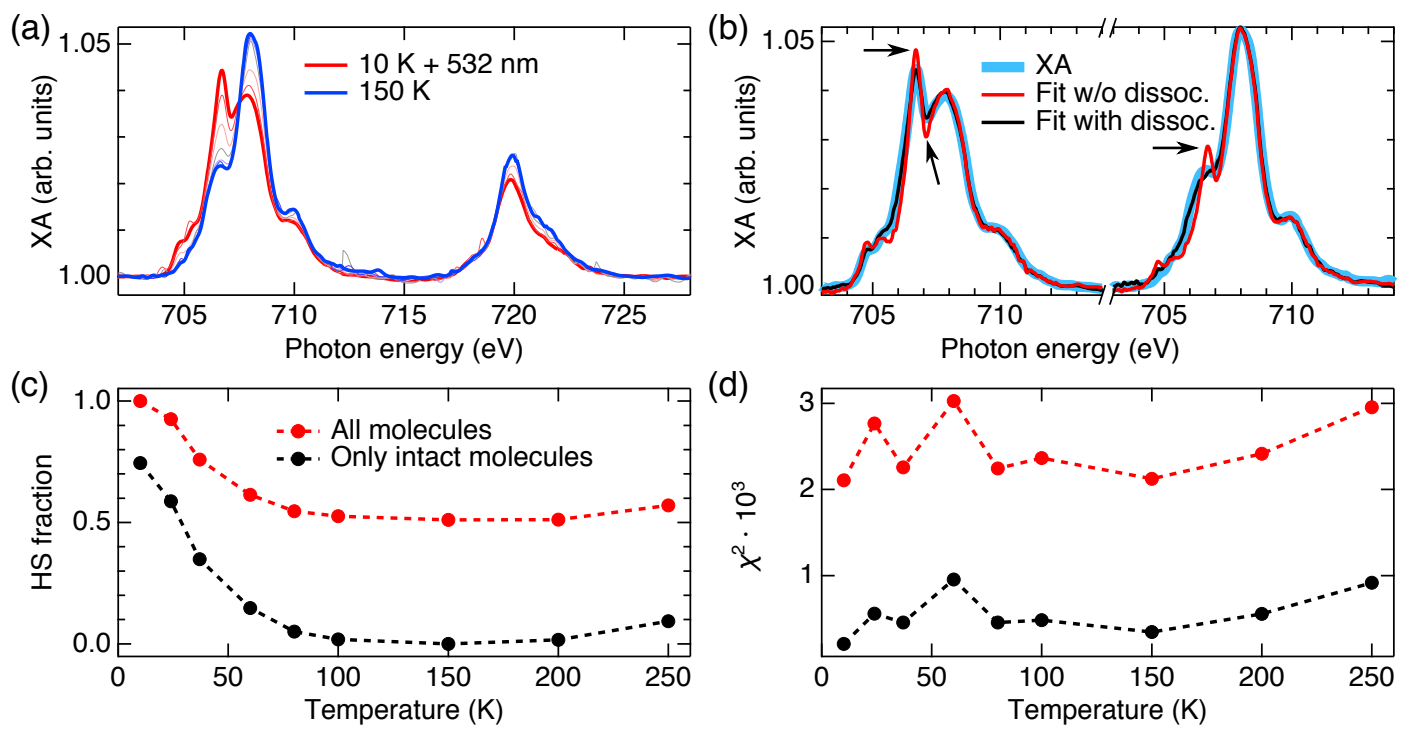

Figure 6. Coexistence of functional and fragmented complexes 9 in direct contact with graphene/Ni(111). (a) XA spectra acquired on $0.4 \mathrm{ML}$ of 9 on graphene/ $\mathrm{Ni}(111)$ at different temperatures $(10,24,37,60,80,100,150 \mathrm{~K}$ from red to blue) under illumination with a $532 \mathrm{~nm}$ laser. (b) XA measured at 10 (under illumination) and $150 \mathrm{~K}$ along with fits to Equation (1) (red) and to Equation (13) (black). The fit that takes into account a fraction of fragmented molecules (black curve) significantly better describes the experimental data (bluish curve) compared to the fit solely considering HS and LS molecules (red curves). Some deviations of the later fit to the experimental data are highlighted with arrows. (c) Evolution of the fraction of HS molecules and (d) deviation of the data to the fits $\left(\chi^{2}\right)$ as a function of temperature by considering all the molecules intact (black) or by considering a fraction of fragmented molecules (red). A detailed description of the fits and experimental methods can be found in Ref. [24].

Noticing that the deviations are located close to the HS feature at $706.7 \mathrm{eV}$, and remembering that the fragmented complex 9 on $\mathrm{Au}(111)$ has a dominant peak at $706.6 \mathrm{eV}$ (Figure $4 \mathrm{~b}$ ), these deviations may be due to the presence of fragmented molecules. We therefore extended Equation (1) to include fragments:

$$
X A S_{\text {mix }}=a\left\{\gamma_{\text {Frag. }} X A S_{\text {Frag. }}+\left(1-\gamma_{\text {Frag. }}\right)\left[\gamma_{\mathrm{HS}} X A S_{\mathrm{HS}}+\left(1-\gamma_{\mathrm{HS}}\right) X A S_{\mathrm{LS}}\right]\right\},
$$

where $\gamma_{\text {Frag. }}$ and $X A S_{\text {Frag. }}$ are the fraction and the XA spectrum of fragmented molecules, respectively. For $X A S_{\text {Frag. }}$ we use the XA spectrum acquired on $\mathrm{Au}(111)$ (Figure $4 \mathrm{~b}$ ).

A fit of the XA spectra with Equation (13) leads to a much better agreement with the experimental data (compare black and blue curves in Figure 6b). In particular, the initial deviations indicated by arrows are essentially absent. To compare the quality of the fits to Equations (1) and (13), the corresponding sums of the squared difference $\left(\chi^{2}\right)$ are shown in Figure $6 \mathrm{~d}$. The squared difference associated to fit with Equation (13) (black) is systematically significantly lower than that of a fit with Equation (1) (red). It should be mentioned that, to effectively reduce the number of fit parameters, we performed a global fit where $\gamma_{\text {Frag. }}$ is the same for all temperatures. The best agreement is found for $\gamma_{\text {Frag. }}=30 \%$. The fragmentation is most probably due to an imperfect graphene layer with reactive defects.

Given the significant improvement of the fits with Equation (13), we strongly favor the scenario involving fragmented molecules. Focusing on the intact complexes, the evolution of the HS fraction with temperature (under illumination with $532 \mathrm{~nm}$ laser at low temperatures) is as shown by the black markers in Figure 6c. Approximately $10 \%$ of the intact complexes are in the HS state at $250 \mathrm{~K}$, the HS fraction reduces to $\approx 0$ for temperatures between 100 and $200 \mathrm{~K}$, and the complexes experience LIESST and SOXIESST at lower temperatures. We believe that HS fraction of $100 \%$ could be reached at low 
temperatures upon application of a larger laser intensity. It turns out that the data can actually be better described without postulating a portion of the molecules locked in a given spin state [24].

While the distinction between fragmented molecules and complexes locked in a given spin state may appear of marginal importance, it can turn out fundamental for the interpretation of data on other samples. Figure 7 shows XA spectra of a peculiar sample composed of $0.2 \mathrm{ML}$ of 9 on $\mathrm{Au}(111)$ acquired at different temperatures. There is clear evolution in the successive spectra, and an analysis using Equation (1) yields half of the complexes locked in the HS while the other half exhibits temperature and $\mathrm{X}$-ray induced switching (red markers in Figure $7 \mathrm{~b}$ ). However, here again, the data are better described by considering $\approx 30 \%$ of fragmented molecules and the remaining ones functional (black markers in Figure 7b) [24]. Nonetheless, two aspects are rather surprising. (i) Why would only a fraction of the molecules be fragmented on an homogeneous surface such as $\mathrm{Au}(111)$ ? (ii) How can these results be compatibles with those measured on other samples of sub-ML coverages of 9 on $\mathrm{Au}(111)$ (see for instance Figure 4b)?
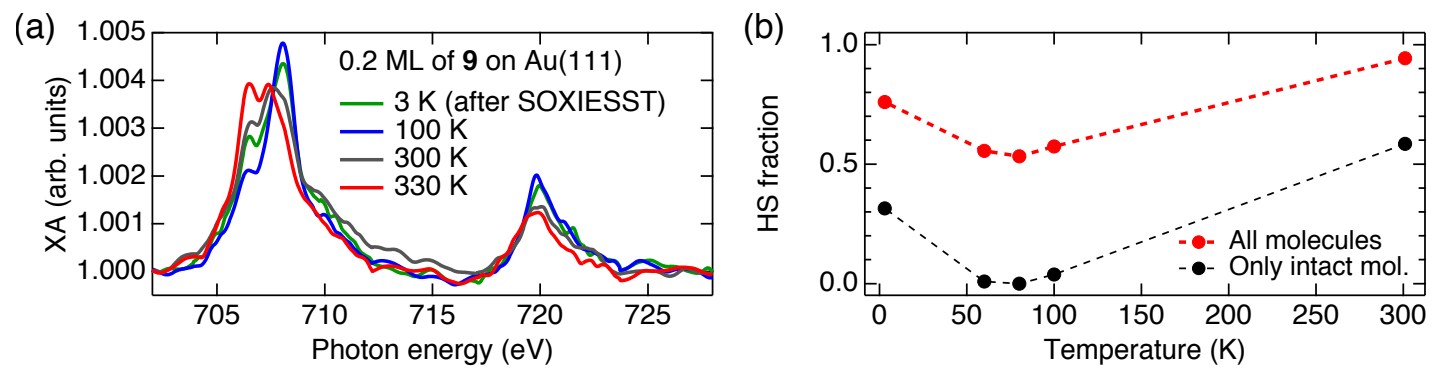

Figure 7. Peculiar results of $0.2 \mathrm{ML}$ of 9 on $\mathrm{Au}(111)$. (a) XA spectra acquired at $3,100,300$ and $330 \mathrm{~K}$ on $0.2 \mathrm{ML}$ of 9 on $\mathrm{Au}(111)$. (b) Evolution of the HS fraction as a function of temperature evaluated by solely considering HS and LS molecules (red) or by accounting for fragmented complexes (black). Importantly, this sample was obtained after insufficient degassing of the Knudsen cell, such that the functional complexes may effectively be adsorbed atop a layer of contaminants instead of the $\mathrm{Au}(111)$ surface. Subsequent (clean) preparation of similar samples led to spectra of fragmented complexes, such as shown in Figure 4. Further description of the experimental methods is available in Ref. [24].

Actually, the sample measured in Figure 7 is the first preparation of the beamtime, realized with insufficient degassing of the Knudsen cell. Most likely a significant amount of fragments, originating from the degassing of the Knudsen cell, arrived at the sample during the deposition of 9. Some of the complexes 9, in direct contact with the $\mathrm{Au}(111)$ surface, fragmented, while those adsorbed on the decoupled layer of fragments remained intact and functional. In agreement with this scenario, the subsequent $\mathrm{Au}(111)$ samples, prepared upon sufficient degassing of the Knudsen cell, exhibited only fragmented molecules.

This observation of a peculiar sample points out issues related to sample preparation and the limits of NEXAFS in providing information about the sample quality. In unfortunate cases, impurities (e.g., fragments) may be continuously co-deposited with the complex of interest even after long degassing of the Knudsen cell. For such cases, the observations that were peculiar in the present case, would be reproducible. As a further point of caution, the presence/absence of impurities is also challenging to demonstrate with (low-resolution) room-temperature STM, that may be available at end stations. It is not uncommon to observe STM images effectively void of features except, for instance, step edges. This can be the result of low resolution (blunt tip, $z$ noise, etc.) and/or diffusion of adsorbates while the tip is scanned over the surface. The observation of the herringbone reconstruction of $\mathrm{Au}(111)$ is one indication of the absence of impurity, but the reconstruction may also be observed atop a layer of organic molecules [92].

Despite the limits of NEXAFS, the technique was and will continue to be crucial for the development of the field. Nonetheless, the limits described in this review should be taken into account in future work and in appreciating the claims made in some previous publications. 


\section{Identification of the Spin States with STM}

NEXAFS provides a direct readout of the spin state of the investigated SCO complexes. However, the method is not applicable at the scale of individual molecules, for which low-temperature STM is employed. While reversible switching of single molecules was clearly observed [25,29-32,34,38,59,67], the identification of the spin states relies on indirect methods.

Compound 1 on $\mathrm{Cu}_{2} \mathrm{~N} / \mathrm{Cu}(100)$ (Figure 8a) exhibits reversible switching upon electron injection/removal with the STM tip. Figure 8b shows a STM image of two complexes, one in the LS state (left) and the other in the HS state (right). The complex in the HS state has a larger apparent height in the center (purple area), which can be visualized in the line profiles displayed in Figure 8c. The change in apparent height between the LS and HS states is on the order of $10 \%$ and reflects the change in geometry and of the electronic properties associated to spin switching.

(a)

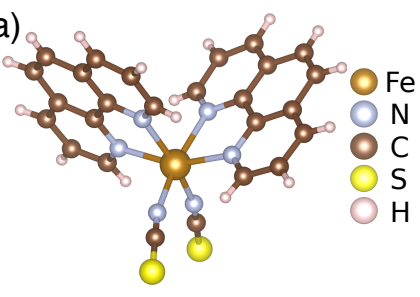

(d)

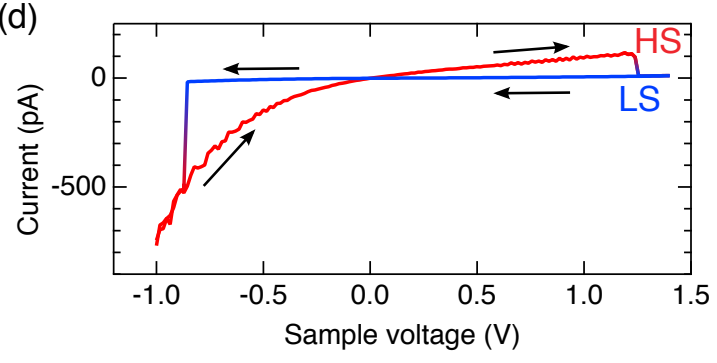

(b)

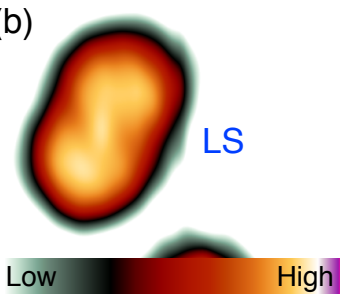

(c)

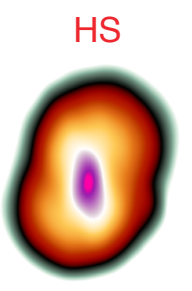

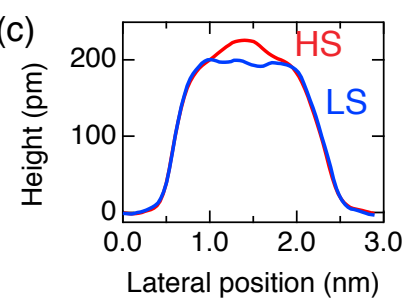

(e)

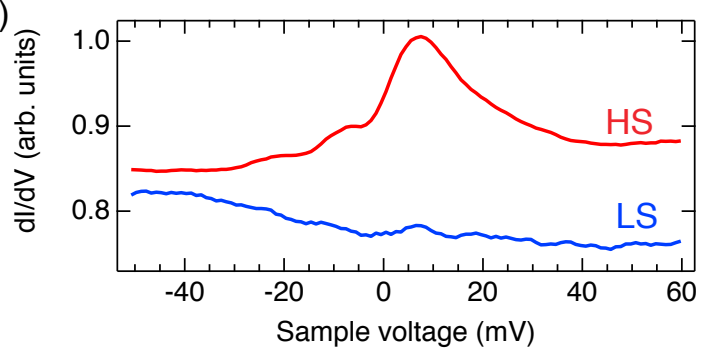

Figure 8. Spin-state identification of 1 on $\mathrm{Cu}_{2} \mathrm{~N} / \mathrm{Cu}(100)$. (a) Molecular structure of 1 composed of two phenanthroline and two thiocyanate ligands. (b) Constant-current STM topograph of two individual molecules 1 on $\mathrm{Cu}_{2} \mathrm{~N} / \mathrm{Cu}(100)$. The color scale is shown in the lower left inset. (c) Height profiles of the images shown in (b). (d) Current-voltage characteristics acquired with the tip positioned over the center of a complex at a constant height (tip stabilized at $1 \mathrm{~V}, 100 \mathrm{pA}$ ). The arrows indicate the direction of the voltage sweep. (e) Differential-conductance spectra acquired on 1 in the HS (red) and in the (LS) (blue) states. Further description of the experimental methods is available in Ref. [30].

Typical current-voltage curves (voltage swept up and down) are shown in Figure 8d. The LS and HS states are associated with a low- (blue) and high-conductance states (red), respectively. At sample voltages of $\approx-0.9 \mathrm{~V}$ and $\approx+1.2 \mathrm{~V}$, transitions are observed and correspond to spin-state switching [30]. The relationship between conductance and spin states allows to readily identify the spin state from the tunneling current for a fixed tip-sample distance. However, as will be further developed below, the conductance may evolve in a non-trivial way with the sample voltage and with the position of the tip (lateral and vertical). Without a knowledge of the evolution of the conductances, the identification of the conductance/spin pairs with auxiliary measurements should be done under similar conditions (voltage and tip position) as the current- or conductance-based spin-state readout. In addition, it may be worth mentioning that both the geometry and electronic-properties changes associated with spin-state switching have an effect on the observed apparent height and conductance. It is quite challenging to unambiguously disentangle the respective geometric and electronic contributions.

The LS and HS states of $\mathrm{Fe}^{2+}$ SCO complexes are diamagnetic and paramagnetic, respectively. The adsorption of a paramagnetic compound on a surface can lead to a so-called Kondo effect [93,94], a many-body effect where the conduction electrons of the substrate essentially screen the magnetic moment of the molecule. The effect is characterized by a resonance in the differential conductance 
localized close to the Fermi level. As a necessary condition for the observation of a Kondo resonance is unpaired electrons (a magnetic moment) in the complex, this effect, when present, is a clear signature of the HS state. For compound 1 on $\mathrm{Cu}_{2} \mathrm{~N}$, a feature close to the Fermi level (red curve in Figure 8e) is observed only for the complex ascribed to the HS state (compare for instance with the blue curve acquired on a LS complex).

Arguably, the appearance/disappearance of a Kondo resonance upon the switching of the complex is the so far best evidence for spin-state switching. However, there are further requirements for the observation of a Kondo resonance at a given (low) temperature, such as a strong electronic coupling between the magnetic center and the substrate. While these conditions have been met for other molecule/substrate systems [30,34,38], such a resonance is not systematically observed (see, e.g., Ref. [59]). In addition, it is rather challenging to unambiguously prove that a resonance close to zero bias is due to a Kondo effect [95].

Should the change in geometry be significant, the spin state may be read from STM topographs. This is for instance the case for the $\mathrm{Fe}^{3+}$ compound 8 (Figure 9a). Injection of electrons $(V>1.8 \mathrm{~V})$ with the tip of a STM in 8 adsorbed on $\mathrm{Cu}_{2} \mathrm{~N}$ leads to an efficient switching between three different states A-C (Figure 9b-d). State A has a more elongated shape than B, C and from comparison with density function theory calculations is compatible with the HS state. B and C are both compatible with the LS state, and atomically resolved data [67] suggest that it is the same molecular state but differently coupled to the substrate (different adsorption site).

The spin state may be determined from the transport properties as shown above and demonstrated in several break junction, nano gap, vertical junction, and transistor experiments [12,14,43,56,83,96-99]. However, the spin-state identification is not straightforward. The conductance of the junction is not a sole property of the molecule but strongly depends on the molecule-metal contacts, and more precisely on the spatially integrated overlap of the molecule and electrodes wave functions. In that respect, the spatial extent and the symmetry of the molecular orbitals are crucial [100]. Furthermore, the conductance of the junction may evolve in a non trivial way with the applied voltage. The spin state corresponding to largest conductance (at a given voltage) is therefore hardly predictable.

The complexity of spin-state identification from the conductances is illustrated with the investigation of 8 on $\mathrm{Cu}_{2} \mathrm{~N}$ with STM (Figure 9). As stated above, the complex can be switched between three different states by injecting electrons $(V>1.8 \mathrm{~V})$ at the center of the molecule. Figure $9 \mathrm{f}, \mathrm{g}$ show time series of the tunneling current acquired at respectively 1.9 and $2.5 \mathrm{~V}$. The tip is maintained at a fixed position over the center of the complex during a time series. Switching between three different current levels, corresponding to the three states of the molecules, is observed in the time series. The identification of the different current levels is performed by quickly decreasing the voltage when the molecule is in the state of interest, followed by the acquisition of a topograph [67]. The largest to lowest current levels respectively correspond to states A, C and B at $1.9 \mathrm{~V}$ (Figure 9f) and to states A, $\mathrm{B}$ and $\mathrm{C}$ at $2.5 \mathrm{~V}$ (Figure $9 \mathrm{~g}$ ). In particular, the state of lowest conductance is $\mathrm{B}$ at $1.9 \mathrm{~V}$ while it is $\mathrm{C}$ at $2.5 \mathrm{~V}$. This shows that conductances depend on the voltage, and that an identification of the spin states based on currents requires significant auxiliary measurements [67].

The time series of the tunneling current can be rationalized from the $I(V)$ characteristics of the three states for the same tip-sample separation (Figure 9e). The $I(V)$ curves are crossing each others, forming four different regions. In region $\mathrm{I}$, for sample voltages between 1.2 and $1.7 \mathrm{~V}, \mathrm{C}$ is the state with the largest conductance, followed by B and A. This sequence is consistent with the apparent heights observed at the center of the molecule in the topographs (Figure 9b-d). Different sequences are observed in regions II, III and IV. In regions III and IV, the lowest conductance is respectively observed for state B and C, in agreement with the sequence observed in the time series at 1.9 and $2.5 \mathrm{~V}$ (Figure 9f,g). 
(a)

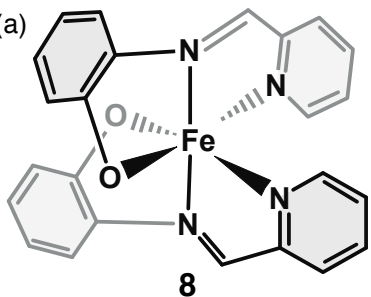

(b)

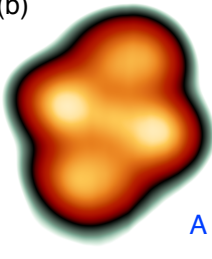

(c)

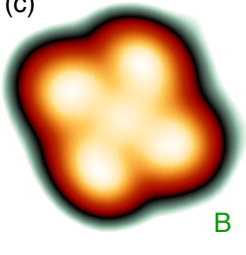

(d)

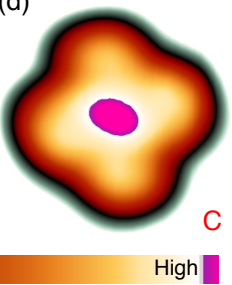

(e)

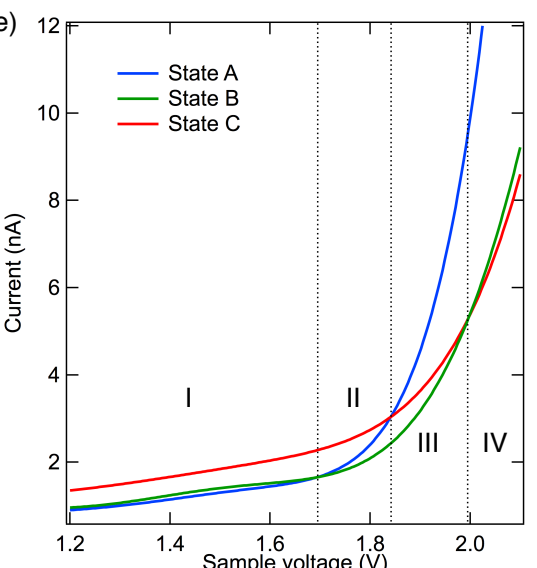

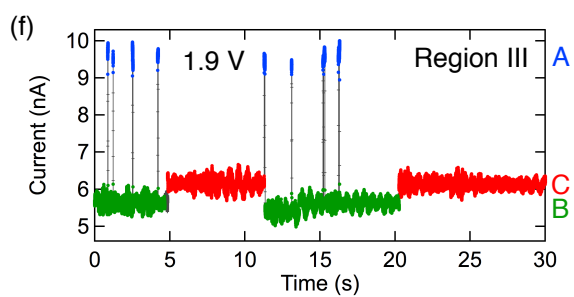

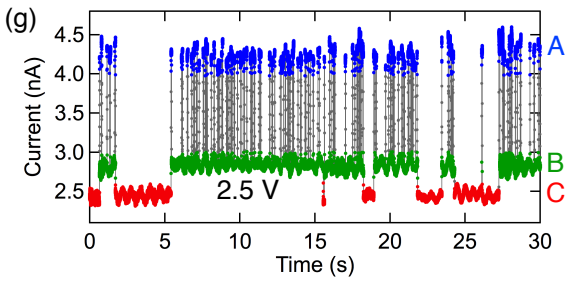

Figure 9. Tunneling current as spin-state readout. (a) Structural model of 8. (b-d) Constant-current STM topographs $\left(2.5 \mathrm{~nm}\right.$ wide) of the same complex 8 on $\mathrm{Cu}_{2} \mathrm{~N} / \mathrm{Cu}(100)$ in states $\mathrm{A}, \mathrm{B}$ and $\mathrm{C}$, respectively. The switching between the states is induced by injection of electrons into the molecule at an elevated voltage $(V>1.8 \mathrm{~V})$. The common colorscale is shown below the topographs. The highest apparent height (magenta) is $215 \mathrm{pm}$. (e) Current-voltage characteristics of the three states. In total, four $I(V)$ where measured for two distinct tip-sample distances. The current-voltage curves of $\mathrm{C}$, measured for the two tip-sample distances, solely differ by a factor 1.52. The $I(V)$ of B was multiplied by the same factor to have a complete set of current-voltage characteristics effectively acquired for the same tip-sample distance. In addition, the shown $I(V)$ are polynomial fits of experimental data (from Ref. [67]) to reduce the associated noise. Vertical dotted lines indicate the voltages at which crossing of $I(V)$ curves take place, and separate four regions. Time series of the tunneling current at a sample voltage of (f) $1.9 \mathrm{~V}$ (region III indicated in (e)) and (g) $2.5 \mathrm{~V}$ (region IV in (e)). (f,g) The color of the markers indicate the state of the molecule (blue, green and red for A, B and C, respectively). Intermediate tunneling currents (gray points) are visible because the data were sampled at a rate $(7 \mathrm{kHz})$ higher than the $I-V$ converter cut-off frequency $(1 \mathrm{kHz})$. Extended description of the experimental methods can be read in Ref. [67].

Tunneling electrons may transfer a part of their energy to vibrational modes of the complex. Such inelastic processes may sometimes be observed as pairwise steps, symmetric about the Fermi level, in differential-conductance spectra [101]. The voltages at which the step-wise increases occur correspond to the energy of the probed vibrational mode. Typically, molecular adsorbates have a wide range of vibrational modes out of which only few lead to significant changes of the current. Bairagi et al. [59] have reported two pairs of step-wise increases $(\approx 18$ and $\approx 67 \mathrm{meV})$ for the complexes 6 on $\mathrm{Au}(111)$ visualized as bright protrusions (see Figure 5 and Ref. [59]). In contrast, the spectrum observed on a molecule in the other configuration only exhibits (very) weak steps at $67 \mathrm{meV}$. The different vibrational spectra observed for HS and LS of 6 on Au(111) may be due to different vibrational modes and/or different electron-phonon couplings. With the help of density functional theory calculations performed on a free molecule, the complexes exhibiting clear inelastic steps have been associated to the HS state. STM-resolved vibrational spectroscopy therefore appears to be useful to identify the spin state of SCO complexes. However, such an identification relies on comparison with calculations. Unfortunately, an accurate description of the system with the available methods and resources is challenging. In the present example from Ref. [59], the calculations were 
performed for a free molecule in contrast to the measurements, which were performed on a monolayer adsorbed on $\mathrm{Au}(111)$.

The spin state identification with STM so far relies on comparison with quantities determined from DFT calculations, or on the presence/absence of a Kondo resonance, which is difficult to unambiguously prove [95]. More direct observations, such as spin excitation spectroscopy, would be desirable. It may be worth mentioning that we observed switching for two SCO systems on $\mathrm{Au}(111)$, for which the accessible data were not sufficient to ascertain the nature of the switching $[25,29]$.

\section{Conclusions}

Since the prototypical demonstrations of single-molecule switching in 2012, the field of SCO complexes in direct contact with surfaces has gained a degree of maturity. Detailed investigations of various complexes along with improved quality of data allowed new discoveries and a better understanding of the mechanisms at play. Nonetheless, these studies also pointed out challenges and limits of the experimental techniques employed to address SCO complexes at sub-ML coverages. These limits are relevant and should be taken into account.

Recent analyses have revealed the fragmentation of SCO systems on metal surfaces. Actually, fragmentation appears to be the rule rather than the exception on metals, and consequently further investigations in that direction have already started. Different strategies are explored in parallel, consisting in the synthesis of more robust compounds [25] and the development of new spin switching designs involving mechanical motion [102-104] or hydrogen abstraction [105,106]. In addition, SCO complexes incorporating a functional switchable ligand have been reported [44] and hold great promises.

Funding: This project has received funding from the European Union's Horizon 2020 research and innovation programme under grant no. 766726 and from the Deutsche Forschungsgemeinschaft through SFB 677 and SFB 668. The work related to thickness determination using NEXAFS has benefited from measurements at the X-Treme beamline at the Swiss Light Source, Switzerland (proposal 20171434) and at the DEIMOS beamline at SOLEIL Synchrotron, France (proposals 20171015 and 20190691).

Acknowledgments: We gratefully acknowledge the contributions of M. Alouani, J. Arabski, L.M. Arruda, A. Bannwarth, E. Beaurepaire, S. Bernhard, M. Bernien, M.L. Bocquet, S. Boukari, M. Bowen, T. Brandl, A. Buchholz, F. Choueikani, V. Da Costa, Y.J. Dappe, V. Davesne, F. Diekmann, W.H. Doh, B.M. Flöser, A.B. Gaspar, C. González, T.G. Gopakumar, J. Grunwald, S. Gueddida, F. Gutzeit, C. Hamann, G.D. Harzmann, N. Hauptmann, R. Herges, C.F. Hermanns, I.P. Hong, D. Häussinger, H. Jacob, S. Jarausch, T. Jasper-Toennies, S. Johannsen, L. Joly, M. Kalläne, S. Karan, L. Kipgen, T. Knaak, A. Krüger, D. Krüger, W. Kuch, A. Köbke, D. Longo, N. Lorente, F. Matino, M. Mayor, T. Miyamachi, S. Mühlenberend, H. Naggert, F. Nickel, C. Näther, P. Ohresser, S. Ossinger, E. Otero, W. Plass, A. Prescimone, A. Rai, J.A. Real, G. Rogez, S. Rohlf, K. Rossnagel, M. Ruben, J. Rudnik, F. Röhricht, F. Scheurer, A. Schlimm, G. Schmerber, M.G. Silly, F. Sirotti, M. Studniarek, N. Suryadevara, F. Tuczek, W. Walter, W. Weber, A. Weismann, R. Woltmann, W. Wulfhekel, T.K. Yamada, and S. Zafeiratos to our work on SCO compounds at surfaces. We are grateful to the staff of the Swiss Light Source and SOLEIL synchrotrons for smoothly running the facilities.

Conflicts of Interest: The authors declare no conflict of interest.

\section{Abbreviations}

The following abbreviations are used in this manuscript:

HOPG Highly oriented pyrolytic graphite

HS High spin

LIESST Light-induced excited spin-state trapping

LS Low spin

ML Monolayer

NEXAFS Near-edge $X$-ray absorption fine structure

SCO Spin crossover

SOXIESST Soft X-ray induced excited spin-state trapping

STM Scanning tunneling microscopy

TEY Total electron yield 


\section{Appendix A}

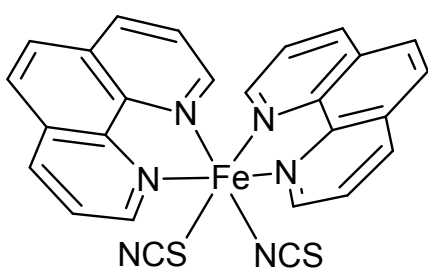

1

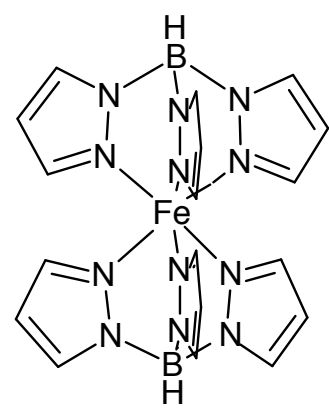

4

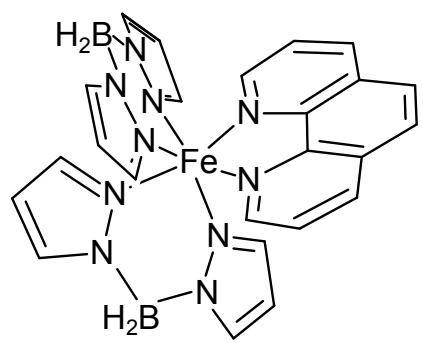

2

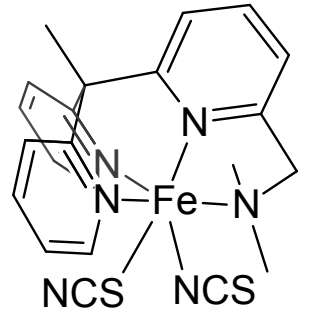

5

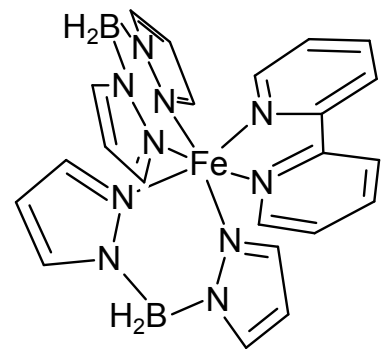

3

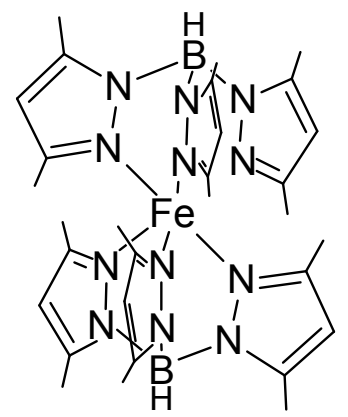

6
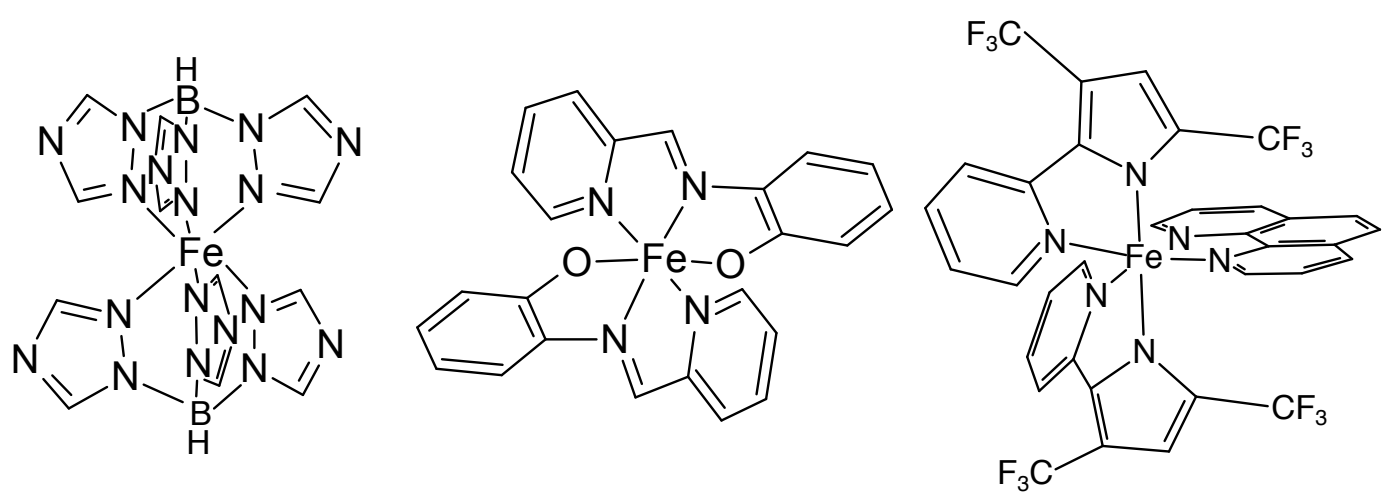

7

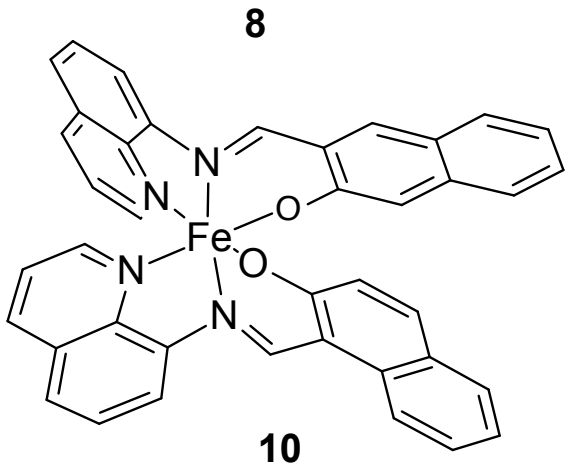

Figure A1. Structural models of the compounds listed in Table 1. 


\section{References}

1. Gütlich, P.; Garcia, Y.; Goodwin, H.A. Spin crossover phenomena in Fe (II) complexes. Chem. Soc. Rev. 2000, 29, 419-427. [CrossRef]

2. Halcrow, M.A. Spin-Crossover Materials: Properties and Applications, 1st ed.; Wiley: Chichester, UK, 2013.

3. Kahn, O.; Kröber, J.; Jay, C. Spin Transition Molecular Materials for displays and data recording. Adv. Mater. 1992, 4, 718-728. [CrossRef]

4. Shepherd, H.J.; Molnár, G.; Nicolazzi, W.; Salmon, L.; Bousseksou, A. Spin Crossover at the Nanometre Scale. Eur. J. Inorg. Chem. 2012, 2013, 653-661. [CrossRef]

5. Molnár, G.; Salmon, L.; Nicolazzi, W.; Terki, F.; Bousseksou, A. Emerging properties and applications of spin crossover nanomaterials. J. Mater. Chem. 2014, 2, 1360. [CrossRef]

6. Molnár, G.; Rat, S.; Salmon, L.; Nicolazzi, W.; Bousseksou, A. Spin Crossover Nanomaterials: From Fundamental Concepts to Devices. Adv. Mater. 2017, 2017, 17003862. [CrossRef] [PubMed]

7. Shepherd, H.J.; Gural'skiy, I.A.; Quintero, C.M.; Tricard, S.; Salmon, L.; Molnár, G.; Bousseksou, A. Molecular actuators driven by cooperative spin-state switching. Nat. Commun. 2013, 4, 2607. [CrossRef] [PubMed]

8. Diaconu, A.; Lupu, S.L.; Rusu, I.; Risca, I.M.; Salmon, L.; Molnár, G.; Bousseksou, A.; Demont, P.; Rotaru, A. Piezoresistive Effect in the $\left[\mathrm{Fe}(\mathrm{Htrz})_{2}(\mathrm{trz})\right]\left(\mathrm{BF}_{4}\right)$ Spin Crossover Complex. J. Phys. Chem. Lett. 2017, 8, 3147-3151. [CrossRef]

9. Kahn, O.; Martinez, C.J. Spin-transition polymers: From molecular materials toward memory devices. Science 1998, 279, 44-48. [CrossRef]

10. Shalabaeva, V.; Ridier, K.; Rat, S.; Manrique-Juarez, M.D.; Salmon, L.; Séguy, I.; Rotaru, A.; Molnár, G.; Bousseksou, A. Room temperature current modulation in large area electronic junctions of spin crossover thin films. Appl. Phys. Lett. 2018, 112, 013301. [CrossRef]

11. Hao, G.; Mosey, A.; Jiang, X.; Yost, A.J.; Sapkota, K.R.; Wang, G.T.; Zhang, X.; Zhang, J.; N’Diaye, A.T.; Cheng, R.; et al. Nonvolatile voltage controlled molecular spin state switching. Appl. Phys. Lett. 2019, 114, 032901. [CrossRef]

12. Gee, A.; Jaafar, A.H.; Brachňaková, B.; Massey, J.; Marrows, C.H.; Šalitroš, I.; Kemp, N.T. Multilevel Resistance Switching and Enhanced Spin Transition Temperature in Single- and Double-Molecule Spin Crossover Nanogap Devices. J. Phys. Chem. C 2020, 124, 13393-13399. [CrossRef]

13. Zhang, Y.; Séguy, I.; Ridier, K.; Shalabaeva, V.; Piedrahita-Bello, M.; Rotaru, A.; Salmon, L.; Molnár, G.; Bousseksou, A. Resistance switching in large-area vertical junctions of the molecular spin crossover complex $\left[\mathrm{Fe}\left(\mathrm{HB}(\mathrm{tz})_{3}\right)_{2}\right]$ : ON/OFF ratios and device stability. J. Phys. Condens. Matter 2020, 32, 214010. [CrossRef] [PubMed]

14. Geest, E.P.; Shakouri, K.; Fu, W.; Robert, V.; Tudor, V.; Bonnet, S.; Schneider, G.F. Contactless Spin Switch Sensing by Chemo-Electric Gating of Graphene. Adv. Mater. 2020, 32, 1903575. [CrossRef] [PubMed]

15. Linares, J.; Codjovi, E.; Garcia, Y. Pressure and Temperature Spin Crossover Sensors with Optical Detection. Sensors 2012, 12, 4479-4492. [CrossRef] [PubMed]

16. Bartual-Murgui, C.; Akou, A.; Thibault, C.; Molnár, G.; Vieu, C.; Salmon, L.; Bousseksou, A. Spin-crossover metal-organic frameworks: Promising materials for designing gas sensors. J. Mater. Chem. C 2015, 3, 1277-1285. [CrossRef]

17. Jureschi, C.; Linares, J.; Rotaru, A.; Ritti, M.; Parlier, M.; Dîrtu, M.; Wolff, M.; Garcia, Y. Pressure Sensor via Optical Detection Based on a 1D Spin Transition Coordination Polymer. Sensors 2015, 15, 2388-2398. [CrossRef]

18. Jureschi, C.M.; Linares, J.; Boulmaali, A.; Dahoo, P.; Rotaru, A.; Garcia, Y. Pressure and Temperature Sensors Using Two Spin Crossover Materials. Sensors 2016, 16, 187. [CrossRef]

19. Boukheddaden, K.; Ritti, M.H.; Bouchez, G.; Sy, M.; Dîrtu, M.M.; Parlier, M.; Linares, J.; Garcia, Y. Quantitative Contact Pressure Sensor Based on Spin Crossover Mechanism for Civil Security Applications. J. Phys. Chem. C 2018, 122, 7597-7604. [CrossRef]

20. Benaicha, B.; Van Do, K.; Yangui, A.; Pittala, N.; Lusson, A.; Sy, M.; Bouchez, G.; Fourati, H.; Gómez-García, C.J.; Triki, S.; et al. Interplay between spin-crossover and luminescence in a multifunctional single crystal iron(ii) complex: Towards a new generation of molecular sensors. Chem. Sci. 2019, 10, 6791-6798. [CrossRef] 
21. Bousseksou, A.; Molnár, G.; Tuchagues, J.P.; Menéndez, N.; Codjovi, É.; Varret, F. Triggering the spin-crossover of $\mathrm{Fe}(\text { phen })_{2}(\mathrm{NCS})_{2}$ by a pressure pulse. Pressure and magnetic field induce mirror effects. C. R. Chim. 2003, 6, 329-335. [CrossRef]

22. Halcrow, M.A. Manipulating metal spin states for biomimetic, catalytic and molecular materials chemistry. Dalton Trans. 2020. [CrossRef] [PubMed]

23. Rohlf, S.; Gruber, M.; Flöser, B.M.; Grunwald, J.; Jarausch, S.; Diekmann, F.; Kalläne, M.; Jasper-Toennies, T.; Buchholz, A.; Plass, W.; et al. Light-Induced Spin Crossover in an Fe(II) Low-Spin Complex Enabled by Surface Adsorption. J. Phys. Chem. Lett. 2018, 9, 1491-1496. [CrossRef] [PubMed]

24. Rohlf, S.; Grunwald, J.; Jasper-Toennies, T.; Johannsen, S.; Diekmann, F.; Studniarek, M.; Berndt, R.; Tuczek, F.; Rossnagel, K.; Gruber, M. Influence of Substrate Electronic Properties on the Integrity and Functionality of an Adsorbed Fe(II) Spin-Crossover Compound. J. Phys. Chem. 2019, 123, 17774. [CrossRef]

25. Brandl, T.; Johannsen, S.; Häussinger, D.; Suryadevara, N.; Prescimone, A.; Bernhard, S.; Gruber, M.; Ruben, M.; Berndt, R.; Mayor, M. Iron in a cage: Fixation of a Fe(II)tpy2 complex by fourfold interlinking. Angew. Chem. Int. Ed. 2020. [CrossRef]

26. Hamann, C.; Woltmann, R.; Hong, I.P.; Hauptmann, N.; Karan, S.; Berndt, R. Ultrahigh vacuum deposition of organic molecules by electrospray ionization. Rev. Sci. Instrum. 2011, 82, 033903. [CrossRef]

27. Shi, S.; Schmerber, G.; Arabski, J.; Beaufrand, J.B.; Kim, D.J.; Boukari, S.; Bowen, M.; Kemp, N.T.; Viart, N.; Rogez, G.; et al. Study of molecular spin-crossover complex Fe(phen $)_{2}(\mathrm{NCS})_{2}$ thin films. Appl. Phys. Lett. 2009, 95, 043303. [CrossRef]

28. Kumar, K.S.; Ruben, M. Sublimable Spin Crossover Complexes: From Spin-State Switching to Molecular Devices. Angew. Chem. 2019. [CrossRef]

29. Jasper-Tönnies, T.; Gruber, M.; Karan, S.; Jacob, H.; Tuczek, F.; Berndt, R. Deposition of a Cationic FeIII Spin-Crossover Complex on Au(111): Impact of the Counter Ion. J. Phys. Chem. Lett. 2017, 8, 1569-1573. [CrossRef]

30. Miyamachi, T.; Gruber, M.; Davesne, V.; Bowen, M.; Boukari, S.; Joly, L.; Scheurer, F.; Rogez, G.; Yamada, T.K.; Ohresser, P.; et al. Robust spin crossover and memristance across a single molecule. Nat. Commun. 2012, 3, 938. [CrossRef]

31. Gruber, M.; Davesne, V.; Bowen, M.; Boukari, S.; Beaurepaire, E.; Wulfhekel, W.; Miyamachi, T. Spin state of spin-crossover complexes: From single molecules to ultrathin films. Phys. Rev. B 2014, 89, 195415. [CrossRef]

32. Gruber, M. Electronic and Magnetic Properties of Hybrid Interfaces. From Single Molecules to Ultra-Thin Molecular Films on Metallic Substrates. Ph.D. Thesis, Univeristy of Strasbourg and Karlsruhe Institute of Technology, Strasbourg, France, 2014.

33. Gueddida, S.; Gruber, M.; Miyamachi, T.; Beaurepaire, E.; Wulfhekel, W.; Alouani, M. Exchange Coupling of Spin-Crossover Molecules to Ferromagnetic Co Islands. J. Phys. Chem. Lett. 2016, 7, 900-904. [CrossRef] [PubMed]

34. Gruber, M.; Miyamachi, T.; Davesne, V.; Bowen, M.; Boukari, S.; Wulfhekel, W.; Alouani, M.; Beaurepaire, E. Spin crossover in Fe(phen $)_{2}(\mathrm{NCS})_{2}$ complexes on metallic surfaces. J. Chem. Phys. 2017, 146, 092312. [CrossRef]

35. Beniwal, S.; Sarkar, S.; Baier, F.; Weber, B.; Dowben, P.A.; Enders, A. Site selective adsorption of the spin crossover complex $\mathrm{Fe}(\text { phen })_{2}(\mathrm{NCS})$ on $\mathrm{Au}(111)$. J. Phys. Condens. Matter 2020, 32, 324003. [CrossRef] [PubMed]

36. Naggert, H.; Bannwarth, A.; Chemnitz, S.; von Hofe, T.; Quandt, E.; Tuczek, F. First observation of light-induced spin change in vacuum deposited thin films of iron spin crossover complexes. Dalton Trans. 2011, 40, 6364-6366. [CrossRef] [PubMed]

37. Palamarciuc, T.; Oberg, J.C.; El Hallak, F.; Hirjibehedin, C.F.; Serri, M.; Heutz, S.; Létard, J.F.; Rosa, P. Spin crossover materials evaporated under clean high vacuum and ultra-high vacuum conditions: From thin films to single molecules. J. Mater. Chem. 2012, 22, 9690-9695. [CrossRef]

38. Gopakumar, T.G.; Matino, F.; Naggert, H.; Bannwarth, A.; Tuczek, F.; Berndt, R. Electron-Induced Spin Crossover of Single Molecules in a Bilayer on Gold. Angew. Chem. Int. Ed. 2012, 51, 6262-6266. [CrossRef]

39. Gopakumar, T.G.; Bernien, M.; Naggert, H.; Matino, F.; Hermanns, C.F.; Bannwarth, A.; Mühlenberend, S.; Krüger, A.; Krüger, D.; Nickel, F.; et al. Spin-Crossover Complex on Au(111): Structural and Electronic Differences Between Mono- and Multilayers. Chem. A Eur. J. 2013, 19, 15702-15709. [CrossRef] 
40. Naggert, H.; Rudnik, J.; Kipgen, L.; Bernien, M.; Nickel, F.; Arruda, L.M.; Kuch, W.; Näther, C.; Tuczek, F. Vacuum-evaporable spin-crossover complexes: Physicochemical properties in the crystalline bulk and in thin films deposited from the gas phase. J. Mater. Chem. C 2015, 3, 7870-7877. [CrossRef]

41. Bernien, M.; Naggert, H.; Arruda, L.M.; Kipgen, L.; Nickel, F.; Miguel, J.; Hermanns, C.F.; Krüger, A.; Krüger, D.; Schierle, E.; et al. Highly Efficient Thermal and Light-Induced Spin-State Switching of an Fe(II) Complex in Direct Contact with a Solid Surface. ACS Nano 2015, 9, 8960-8966. [CrossRef]

42. Ossinger, S.; Naggert, H.; Kipgen, L.; Jasper-Toennies, T.; Rai, A.; Rudnik, J.; Nickel, F.; Arruda, L.M.; Bernien, M.; Kuch, W.; et al. Vacuum-Evaporable Spin-Crossover Complexes in Direct Contact with a Solid Surface: Bismuth versus Gold. J. Phys. Chem. C 2017, 121, 1210-1219. [CrossRef]

43. Schleicher, F.; Studniarek, M.; Kumar, K.S.; Urbain, E.; Katcko, K.; Chen, J.; Frauhammer, T.; Hervé, M.; Halisdemir, U.; Kandpal, L.M.; et al. Linking Electronic Transport through a Spin Crossover Thin Film to the Molecular Spin State Using X-ray Absorption Spectroscopy Operando Techniques. ACS Appl. Mater. Interfaces 2018, 10, 31580-31585. [CrossRef] [PubMed]

44. Poggini, L.; Milek, M.; Londi, G.; Naim, A.; Poneti, G.; Squillantini, L.; Magnani, A.; Totti, F.; Rosa, P.; Khusniyarov, M.; et al. Room temperature control of spin states in a thin film of a photochromic iron(ii) complex. Mater. Horizons 2018, 5, 506-513. [CrossRef]

45. Poggini, L.; Londi, G.; Milek, M.; Naim, A.; Lanzilotto, V.; Cortigiani, B.; Bondino, F.; Magnano, E.; Otero, E.; Sainctavit, P.; et al. Surface effects on a photochromic spin-crossover iron II molecular switch adsorbed on highly oriented pyrolytic graphite. Nanoscale 2019, 11, 20006-20014. [CrossRef]

46. Ossinger, S.; Kipgen, L.; Naggert, H.; Bernien, M.; Britton, A.J.; Nickel, F.; Arruda, L.M.; Kumberg, I.; Engesser, T.A.; Golias, E.; et al. Effect of ligand methylation on the spin-switching properties of surface-supported spin-crossover molecules. J. Phys. Condens. Matter 2020, 32, 114003. [CrossRef] [PubMed]

47. Pronschinske, A.; Bruce, R.C.; Lewis, G.; Chen, Y.; Calzolari, A.; Buongiorno-Nardelli, M.; Shultz, D.A.; You, W.; Dougherty, D.B. Iron(II) spin crossover films on $\mathrm{Au}(111)$ : Scanning probe microscopy and photoelectron spectroscopy. Chem. Commun. 2013, 49, 10446-10452. [CrossRef] [PubMed]

48. Warner, B.; Oberg, J.C.; Gill, T.G.; El Hallak, F.; Hirjibehedin, C.F.; Serri, M.; Heutz, S.; Arrio, M.A.; Sainctavit, P.; Mannini, M.; et al. Temperature- and Light-Induced Spin Crossover Observed by X-ray Spectroscopy on Isolated Fe(II) Complexes on Gold. J. Phys. Chem. Lett. 2013, 4, 1546-1552. [CrossRef]

49. Pronschinske, A.; Chen, Y.; Lewis, G.F.; Shultz, D.A.; Calzolari, A.; Buongiorno Nardelli, M.; Dougherty, D.B. Modification of Molecular Spin Crossover in Ultrathin Films. Nano Lett. 2013, 13, 1429-1434. [CrossRef]

50. Zhang, X.; Palamarciuc, T.; Létard, J.F.; Rosa, P.; Lozada, E.V.; Torres, F.; Rosa, L.G.; Doudin, B.; Dowben, P.A. The spin state of a molecular adsorbate driven by the ferroelectric substrate polarization. Chem. Commun. 2014, 50, 2255-2257. [CrossRef]

51. Zhang, X.; Costa, P.S.; Hooper, J.; Miller, D.P.; N’Diaye, A.T.; Beniwal, S.; Jiang, X.; Yin, Y.; Rosa, P.; Routaboul, L.; et al. Locking and Unlocking the Molecular Spin Crossover Transition. Adv. Mater. 2017, 29, 1702257. [CrossRef]

52. Kipgen, L.; Bernien, M.; Nickel, F.; Naggert, H.; Britton, A.J.; Arruda, L.M.; Schierle, E.; Weschke, E.; Tuczek, F.; Kuch, W. Soft-X-ray-induced spin-state switching of an adsorbed Fe(II) spin-crossover complex. J. Phys. Condens. Matter 2017, 29, 394003. [CrossRef]

53. Kumar, K.S.; Studniarek, M.; Heinrich, B.; Arabski, J.; Schmerber, G.; Bowen, M.; Boukari, S.; Beaurepaire, E.; Dreiser, J.; Ruben, M. Engineering On-Surface Spin Crossover: Spin-State Switching in a Self-Assembled Film of Vacuum-Sublimable Functional Molecule. Adv. Mater. 2018, 30, 1705416. [CrossRef] [PubMed]

54. Wäckerlin, C.; Donati, F.; Singha, A.; Baltic, R.; Decurtins, S.; Liu, S.X.; Rusponi, S.; Dreiser, J. Excited Spin-State Trapping in Spin Crossover Complexes on Ferroelectric Substrates. J. Phys. Chem. C 2018, 122, 8202-8208. [CrossRef]

55. Zhang, X.; N'Diaye, A.T.; Jiang, X.; Zhang, X.; Yin, Y.; Chen, X.; Hong, X.; Xu, X.; Dowben, P.A. Indications of magnetic coupling effects in spin cross-over molecular thin films. Chem. Commun. 2018, 54, 944-947. [CrossRef] [PubMed]

56. Mahfoud, T.; Molnár, G.; Cobo, S.; Salmon, L.; Thibault, C.; Vieu, C.; Demont, P.; Bousseksou, A. Electrical properties and non-volatile memory effect of the $\left[\mathrm{Fe}\left(\mathrm{HB}(\mathrm{pz})_{3}\right)_{2}\right]$ spin crossover complex integrated in a microelectrode device. Appl. Phys. Lett. 2011, 99, 053307. [CrossRef] 
57. Bernien, M.; Wiedemann, D.; Hermanns, C.F.; Krüger, A.; Rolf, D.; Kroener, W.; Müller, P.; Grohmann, A.; Kuch, W. Spin Crossover in a Vacuum-Deposited Submonolayer of a Molecular Iron(II) Complex. J. Phys. Chem. Lett. 2012, 3, 3431-3434. [CrossRef]

58. Davesne, V.; Gruber, M.; Studniarek, M.; Doh, W.H.; Zafeiratos, S.; Joly, L.; Sirotti, F.; Silly, M.G.; Gaspar, A.B.; Real, J.A.; et al. Hysteresis and change of transition temperature in thin films of $\mathrm{Fe}\left\{\left[\mathrm{Me}_{2} \mathrm{Pyrz}_{3}\right] \mathrm{BH}\right\}_{2}$, a new sublimable spin-crossover molecule. J. Chem. Phys. 2015, 142, 194702. [CrossRef]

59. Bairagi, K.; Iasco, O.; Bellec, A.; Kartsev, A.; Li, D.; Lagoute, J.; Chacon, C.; Girard, Y.; Rousset, S.; Miserque, F.; et al. Molecular-scale dynamics of light-induced spin cross-over in a two-dimensional layer. Nat. Commun. 2016, 7, 12212. [CrossRef]

60. Bairagi, K.; Bellec, A.; Fourmental, C.; Iasco, O.; Lagoute, J.; Chacon, C.; Girard, Y.; Rousset, S.; Choueikani, F.; Otero, E.; et al. Temperature-, Light-, and Soft X-ray-Induced Spin Crossover in a Single Layer of FeII-Pyrazolylborate Molecules in Direct Contact with Gold. J. Phys. Chem. C 2017, 122, 727. [CrossRef]

61. Iasco, O.; Boillot, M.L.; Bellec, A.; Guillot, R.; Rivière, E.; Mazerat, S.; Nowak, S.; Morineau, D.; Brosseau, A.; Miserque, F; et al. The disentangling of hysteretic spin transition, polymorphism and metastability in bistable thin films formed by sublimation of bis(scorpionate) Fe(II) molecules. J. Mater. Chem. C 2017, 5, 11067. [CrossRef]

62. Fourmental, C.; Mondal, S.; Banerjee, R.; Bellec, A.; Garreau, Y.; Coati, A.; Chacon, C.; Girard, Y.; Lagoute, J.; Rousset, S.; et al. Importance of Epitaxial Strain at a Spin-Crossover Molecule-Metal Interface. J. Phys. Chem. Lett. 2019, 10, 4103-4109. [CrossRef]

63. Zhang, L.; Tong, Y.; Kelai, M.; Bellec, A.; Lagoute, J.; Chacon, C.; Girard, Y.; Rousset, S.; Boillot, M.; Rivière, E.; et al. Anomalous Light-Induced Spin-State Switching for Iron(II) Spin-Crossover Molecules in Direct Contact with Metal Surfaces. Angew. Chem. Int. Ed. 2020, 59, 13341-13346. [CrossRef] [PubMed]

64. Shalabaeva, V.; Rat, S.; Manrique-Juarez, M.D.; Bas, A.C.; Vendier, L.; Salmon, L.; Molnár, G.; Bousseksou, A. Vacuum deposition of high-quality thin films displaying spin transition near room temperature. J. Mater. Chem. C 2017, 5, 4419-4425. [CrossRef]

65. Ridier, K.; Bas, A.; Shalabaeva, V.; Nicolazzi, W.; Salmon, L.; Molnár, G.; Bousseksou, A.; Lorenc, M.; Bertoni, R.; Collet, E.; et al. Finite Size Effects on the Switching Dynamics of Spin-Crossover Thin Films Photoexcited by a Femtosecond Laser Pulse. Adv. Mater. 2019, 31, 1901361. [CrossRef]

66. Ridier, K.; Zhang, Y.; Piedrahita-Bello, M.; Quintero, C.M.; Salmon, L.; Molnár, G.; Bergaud, C.; Bousseksou, A. Heat Capacity and Thermal Damping Properties of Spin-Crossover Molecules: A New Look at an Old Topic. Adv. Mater. 2020, 32, 2000987. [CrossRef] [PubMed]

67. Jasper-Toennies, T.; Gruber, M.; Karan, S.; Jacob, H.; Tuczek, F.; Berndt, R. Robust and Selective Switching of an FeIII Spin-Crossover Compound on $\mathrm{Cu}_{2} \mathrm{~N} / \mathrm{Cu}(100)$ with Memristance Behavior. Nano Lett. 2017, 17, 6613. [CrossRef] [PubMed]

68. Atzori, M.; Poggini, L.; Squillantini, L.; Cortigiani, B.; Gonidec, M.; Bencok, P.; Sessoli, R.; Mannini, M. Thermal and light-induced spin transition in a nanometric film of a new high-vacuum processable spin crossover complex. J. Mater. Chem. C 2018, 6, 8885-8889. [CrossRef]

69. Kipgen, L.; Bernien, M.; Ossinger, S.; Nickel, F.; Britton, A.J.; Arruda, L.M.; Naggert, H.; Luo, C.; Lotze, C.; Ryll, H.; et al. Evolution of cooperativity in the spin transition of an iron(II) complex on a graphite surface. Nat. Commun. 2018, 9, 2984. [CrossRef]

70. Knaak, T.; González, C.; Dappe, Y.J.; Harzmann, G.D.; Brandl, T.; Mayor, M.; Berndt, R.; Gruber, M. Fragmentation and Distortion of Terpyridine-Based Spin-Crossover Complexes on Au(111). J. Phys. Chem. C 2019, 123, 4178-4185. [CrossRef]

71. Kumar, K.S.; Ruben, M. Emerging trends in spin crossover (SCO) based functional materials and devices. Coord. Chem. Rev. 2017, 346, 176-205. [CrossRef]

72. Kuch, W.; Bernien, M. Controlling the magnetism of adsorbed metal-organic molecules. J. Phys. Condens. Matter 2017, 29, 023001. [CrossRef]

73. Collison, D.; Garner, C.D.; McGrath, C.M.; Mosselmans, J.F.W.; Roper, M.D.; Seddon, J.M.W.; Sinn, E.; Young, N.A. Soft X-ray induced excited spin state trapping and soft X-ray photochemistry at the iron $\mathrm{L}_{2,3}$ edge in $\left[\mathrm{Fe}(\mathrm{phen})_{2}(\mathrm{NCS})_{2}\right]$ and $\left[\mathrm{Fe}(\mathrm{phen})_{2}(\mathrm{NCSe})_{2}\right]$ (phen $=1,10-$ phenanthroline). J. Chem. Soc. Dalton Trans. 1997, 4371-4376. [CrossRef] 
74. Davesne, V.; Gruber, M.; Miyamachi, T.; Da Costa, V.; Boukari, S.; Scheurer, F.; Joly, L.; Ohresser, P.; Otero, E.; Choueikani, F.; et al. First glimpse of the soft X-ray induced excited spin-state trapping effect dynamics on spin cross-over molecules. J. Chem. Phys. 2013, 139, 074708. [CrossRef] [PubMed]

75. Hauser, A. Light-Induced Spin Crossover and the High-Spin $\rightarrow$ Low-Spin Relaxation. In Spin Crossover in Transition Metal Compounds II; Number 234 in Topics in Current Chemistry; Springer: Berlin/Heidelberg, Germany, 2004; pp. 155-198.

76. Hauser, A. Reversibility of light-induced excited spin state trapping in the $\mathrm{Fe}(\mathrm{ptz})_{6}\left(\mathrm{BF}_{4}\right)_{2}$, and the $\mathrm{Zn}_{1-\mathrm{x}} \mathrm{Fe}_{\mathrm{x}}(\mathrm{ptz})_{6}\left(\mathrm{BF}_{4}\right)_{2}$ spin-crossover systems. Chem. Phys. Lett. 1986, 124, 543-548. [CrossRef]

77. Nakajima, R.; Stöhr, J.; Idzerda, Y.U. Electron-yield saturation effects in L-edge X-ray magnetic circular dichroism spectra of Fe, Co, and Ni. Phys. Rev. B 1999, 59, 6421-6429. [CrossRef]

78. Stöhr, J. Nexafs Spectroscopy; Springer: Berlin/Heidelberg, Germany, 1996.

79. Akgül, G.; Aksoy, F.; Bozduman, A.; Ozkendir, O.; Ufuktepe, Y.; Lüning, J. Study of the $\mathrm{L}_{2}, 3$ edges of $3 \mathrm{~d}$ transition metals by X-ray absorption spectroscopy. Thin Solid Film 2008, 517, 1000-1004. [CrossRef]

80. Costa Pinto, P.; Calatroni, S.; Neupert, H.; Letant-Delrieux, D.; Edwards, P.; Chiggiato, P.; Taborelli, M.; Vollenberg, W.; Yin-Vallgren, C.; Colaux, J.; et al. Carbon coatings with low secondary electron yield. Vacuum 2013, 98, 29-36. [CrossRef]

81. Gonzalez, L.A.; Angelucci, M.; Larciprete, R.; Cimino, R. The secondary electron yield of noble metal surfaces. AIP Adv. 2017, 7, 115203. [CrossRef]

82. Harzmann, G.D.; Frisenda, R.; van der Zant, H.S.J.; Mayor, M. Single-Molecule Spin Switch Based on Voltage-Triggered Distortion of the Coordination Sphere. Angew. Chem. Int. Ed. 2015, 54, 13425-13430. [CrossRef]

83. Frisenda, R.; Harzmann, G.D.; Celis Gil, J.A.; Thijssen, J.M.; Mayor, M.; van der Zant, H.S.J. Stretching-Induced Conductance Increase in a Spin-Crossover Molecule. Nano Lett. 2016, 16, 4733-4737. [CrossRef]

84. Jasper-Tönnies, T.; Poltavsky, I.; Ulrich, S.; Moje, T.; Tkatchenko, A.; Herges, R.; Berndt, R. Stability of functionalized platform molecules on Au(111). J. Chem. Phys. 2018, 149, 244705. [CrossRef]

85. Jasper-Tönnies, T.; Gruber, M.; Ulrich, S.; Herges, R.; Berndt, R. Coverage-Controlled Superstructures of $\mathrm{C}_{3}$-Symmetric Molecules: Honeycomb versus Hexagonal Tiling. Angew. Chem. 2020, 132, 7074-7083. [CrossRef]

86. Ludwig, E.; Naggert, H.; Kalläne, M.; Rohlf, S.; Kröger, E.; Bannwarth, A.; Quer, A.; Rossnagel, K.; Kipp, L.; Tuczek, F. Iron(II) Spin-Crossover Complexes in Ultrathin Films: Electronic Structure and Spin-State Switching by Visible and Vacuum-UV Light. Angew. Chem. Int. Ed. 2014, 53, 3019-3023. [CrossRef] [PubMed]

87. Boldog, I.; Gaspar, A.B.; Martínez, V.; Pardo-Ibañez, P.; Ksenofontov, V.; Bhattacharjee, A.; Gütlich, P.; Real, J.A. Spin-Crossover Nanocrystals with Magnetic, Optical, and Structural Bistability Near Room Temperature. Angew. Chem. Int. Ed. 2008, 47, 6433-6437. [CrossRef] [PubMed]

88. Volatron, F.; Catala, L.; Rivière, E.; Gloter, A.; Stéphan, O.; Mallah, T. Spin-Crossover Coordination Nanoparticles. Inorg. Chem. 2008, 47, 6584-6586. [CrossRef] [PubMed]

89. Raza, Y.; Volatron, F.; Moldovan, S.; Ersen, O.; Huc, V.; Martini, C.; Brisset, F.; Gloter, A.; Stéphan, O.; Bousseksou, A.; et al. Matrix-dependent cooperativity in spin crossover Fe(pyrazine) $\mathrm{Pt}(\mathrm{CN})_{4}$ nanoparticles. Chem. Commun. 2011, 47, 11501. [CrossRef]

90. Félix, G.; Nicolazzi, W.; Salmon, L.; Molnár, G.; Perrier, M.; Maurin, G.; Larionova, J.; Long, J.; Guari, Y.; Bousseksou, A. Enhanced Cooperative Interactions at the Nanoscale in Spin-Crossover Materials with a First-Order Phase Transition. Phys. Rev. Lett. 2013, 110, 235701. [CrossRef]

91. Gueddida, S.; Alouani, M. Spin crossover in a single Fe(phen $)_{2}(\mathrm{NCS})_{2}$ molecule adsorbed onto metallic substrates: An ab initio calculation. Phys. Rev. B 2013, 87, 144413. [CrossRef]

92. Gruber, M.; Berndt, R. Manipulation of Cyclohexene-Based Organic Molecules on Various Metallic Substrates. J. Phys. Chem. C 2016, 120, 18642-18650. [CrossRef]

93. Hewson, A.C. The Kondo Problem to Heavy Fermions by Alexander Cyril Hewson. 1993. Available online: https:/ / doi.org/10.1017/CBO9780511470752 (accessed on 1 January 1993).

94. Ternes, M.; Heinrich, A.J.; Schneider, W.D. Spectroscopic manifestations of the Kondo effect on single adatoms. J. Phys. Condens. Matter 2008, 21, 053001. [CrossRef] 
95. Gruber, M.; Weismann, A.; Berndt, R. The Kondo resonance line shape in scanning tunnelling spectroscopy: instrumental aspects. J. Phys. Condens. Matter 2018, 30, 424001. [CrossRef]

96. Meded, V.; Bagrets, A.; Fink, K.; Chandrasekar, R.; Ruben, M.; Evers, F.; Bernand-Mantel, A.; Seldenthuis, J.S.; Beukman, A.; Van der Zant, H.S.J. Electrical control over the Fe (II) spin crossover in a single molecule: Theory and experiment. Phys. Rev. B 2011, 83, 245415. [CrossRef]

97. Prins, F.; Monrabal-Capilla, M.; Osorio, E.A.; Coronado, E.; van der Zant, H.S.J. Room-Temperature Electrical Addressing of a Bistable Spin-Crossover Molecular System. Adv. Mater. 2011, 23, 1545-1549. [CrossRef]

98. Rotaru, A.; Dugay, J.; Tan, R.P.; Guralskiy, I.A.; Salmon, L.; Demont, P.; Carrey, J.; Molnár, G.; Respaud, M.; Bousseksou, A. Nano-electromanipulation of Spin Crossover Nanorods: Towards Switchable Nanoelectronic Devices. Adv. Mater. 2013, 25, 1745-1749. [CrossRef] [PubMed]

99. Lefter, C.; Davesne, V.; Salmon, L.; Molnár, G.; Demont, P.; Rotaru, A.; Bousseksou, A. Charge Transport and Electrical Properties of Spin Crossover Materials: Towards Nanoelectronic and Spintronic Devices. Magnetochemistry 2016, 2, 18. [CrossRef]

100. Jasper-Tönnies, T.; Garcia-Lekue, A.; Frederiksen, T.; Ulrich, S.; Herges, R.; Berndt, R. Conductance of a Freestanding Conjugated Molecular Wire. Phys. Rev. Lett. 2017, 119, 066801. [CrossRef]

101. Stipe, B.C.; Rezaei, M.A.; Ho, W. Single-Molecule Vibrational Spectroscopy and Microscopy. Science 1998, 280, 1732-1735. [CrossRef]

102. Venkataramani, S.; Jana, U.; Dommaschk, M.; Sönnichsen, F.D.; Tuczek, F.; Herges, R. Magnetic Bistability of Molecules in Homogeneous Solution at Room Temperature. Science 2011, 331, 445-448. [CrossRef] [PubMed]

103. Doistau, B.; Benda, L.; Hasenknopf, B.; Marvaud, V.; Vives, G. Switching Magnetic Properties by a Mechanical Motion. Magnetochemistry 2018, 4, 5. [CrossRef]

104. Köbke, A.; Gutzeit, F.; Röhricht, F.; Schlimm, A.; Grunwald, J.; Tuczek, F.; Studniarek, M.; Longo, D.; Choueikani, F.; Otero, E.; et al. Reversible coordination-induced spin-state switching in complexes on metal surfaces. Nat. Nanotechnol. 2020, 15, 18-21. [CrossRef]

105. Karan, S.; Li, N.; Zhang, Y.; He, Y.; Hong, I.P.; Song, H.; Lü, J.T.; Wang, Y.; Peng, L.; Wu, K.; et al. Spin Manipulation by Creation of Single-Molecule Radical Cations. Phys. Rev. Lett. 2016, 116, 027201. [CrossRef]

106. Bocquet, M.L.; Lorente, N.; Berndt, R.; Gruber, M. Spin in a closed-shell organic molecule on a metal substrate generated by a sigmatropic reaction. Angew. Chem. Int. Ed. 2019, 58, 821-824. [CrossRef] [PubMed]

(C) 2020 by the authors. Licensee MDPI, Basel, Switzerland. This article is an open access article distributed under the terms and conditions of the Creative Commons Attribution (CC BY) license (http://creativecommons.org/licenses/by/4.0/). 